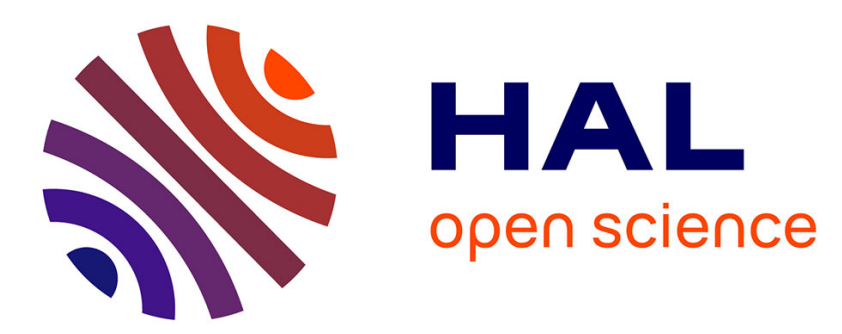

\title{
Selectivity loss in Fischer-Tropsch synthesis: The effect of cobalt carbide formation
}

Paul Hazemann, Dominique Decottignies, Sylvie Maury, Séverine Humbert, Frédéric Meunier, Y. Schuurman

\section{- To cite this version:}

Paul Hazemann, Dominique Decottignies, Sylvie Maury, Séverine Humbert, Frédéric Meunier, et al.. Selectivity loss in Fischer-Tropsch synthesis: The effect of cobalt carbide formation. Journal of Catalysis, 2021, 397, pp.1-12. 10.1016/j.jcat.2021.03.005 . hal-03242403

\section{HAL Id: hal-03242403 https://hal.science/hal-03242403}

Submitted on 4 Jun 2021

HAL is a multi-disciplinary open access archive for the deposit and dissemination of scientific research documents, whether they are published or not. The documents may come from teaching and research institutions in France or abroad, or from public or private research centers.
L'archive ouverte pluridisciplinaire HAL, est destinée au dépôt et à la diffusion de documents scientifiques de niveau recherche, publiés ou non, émanant des établissements d'enseignement et de recherche français ou étrangers, des laboratoires publics ou privés. 


\title{
Selectivity loss in Fischer-Tropsch synthesis: the effect of cobalt carbide formation
}

\author{
Paul Hazemann, ${ }^{a, b}$ Dominique Decottignies, ${ }^{a}$ Sylvie Maury, ${ }^{a}$ Séverine Humbert, ${ }^{a}$ Frederic C. Meunier ${ }^{b}$, \\ Yves Schuurman ${ }^{b^{*}}$ \\ a. IFP Energies nouvelles, Rond-Point de l'Echangeur de Solaize-BP3, Solaize 69360, France \\ b. Univ Lyon, Université Claude Bernard Lyon 1, CNRS, IRCELYON, 2 Avenue Albert Einstein F- \\ 69626, Villeurbanne, France
}

\begin{abstract}
Fischer-Tropsch cobalt catalyst deselectivation was studied using accelerated aging treatments dedicated to the carburization phenomenon. Cobalt carbide was successfully obtained by CO treatments, with limited simultaneously carbon deposition nor sintering. Particle sizes were found to influence the catalyst sensitivity to carburization, likely because of a possible core-shell mechanism. An important loss of both activity and selectivity to heavy products was observed after the treatments, making carburization one of the potential mechanisms responsible for deselectivation in Fischer-Tropsch synthesis. Side products were also impacted by cobalt carbide formation, with an increase of $\mathrm{CO}_{2}$ production and a decrease of the selectivity to olefins. The extent of carburization was found to directly dictate the level of the selectivity shift.
\end{abstract}

Keywords: Cobalt catalysts; Deactivation; Deselectivation; Carburization

\section{Introduction}

Fischer-Tropsch synthesis (FTS) is a promising route for clean fuels [1] and sustainable chemicals production via the $\mathrm{XtL}$ process. Using either biomass $(\mathrm{BtL})$, coal $(\mathrm{CtL})$ or natural gas $(\mathrm{GtL})$ as raw materials, this technology can be an alternative to reduce our petroleum dependency. Fischer-Tropsch catalysts are a key factor to make the process economically viable, since those participate to a large extent in the operational expenses. Cobalt-based catalysts have been widely studied in the last decades due to their high productivity $[2,3]$ and high selectivity [3] toward long chain hydrocarbons, the most valuable products. However, like other Fischer-Tropsch catalysts, those exhibit deactivation and deselectivation [4-7]: both activity and heavy compounds selectivity decrease with time on stream. The scientific community seems to agree on the fact that deactivation results from a combination of several phenomena [4,8] : carbon deposition [9-12], active phase carburization [13-15], water induced effects (re-oxidation [16], sintering [17,18], support hydroxylation [19,20]), but also poisoning [21,22] or even surface reconstruction [17,23]. Much of the research has been focused on the impact of each of these phenomena on activity, but very few have associated 
them with the selectivity shift. Moreover, catalyst performances are often compared at different conversion levels, making conclusions difficult to draw.

Carburization seems to be a particularly good candidate to explain the deselectivation issue. In the literature, carburized cobalt catalysts are often associated with both high $\mathrm{CH}_{4}$ and high oxygenate selectivities. On a Co/ $\mathrm{Al}_{2} \mathrm{O}_{3}$ catalyst carburized by $\mathrm{CO}$ treatment, Claeys et al. [15] observed a doubled $\mathrm{CH}_{4}$ selectivity compared to the fresh catalyst, at low conversion levels $(<15 \%)$. High $\mathrm{CH}_{4}$ and $\mathrm{CO}_{2}$ selectivities were also reported by Mohandas et al. [24], using a cobalt carbide catalyst under relevant industrial FischerTropsch conditions. A significant $\mathrm{CO}_{2}$ selectivity was, moreover, observed on Na-promoted $\mathrm{Co} / \mathrm{SiO}_{2}$ catalysts by Dai et al. [14], exhibiting a significant $\mathrm{Co}_{2} \mathrm{C}$ content. Additionally, Pei et al. [25,26] measured a much higher alcohol selectivity on carburized cobalt catalysts than on a non-carburized catalyst. Because cobalt carbide is not active in FT synthesis, the authors [25] explained this selectivity differences by the creation of the $\mathrm{Co}_{2} \mathrm{C}-\mathrm{Co}^{0}$ interface which facilitates molecularly $\mathrm{CO}$ adsorption and subsequent insertion into hydrocarbon chains, resulting in a higher oxygenate selectivity.

However, despite the obvious selectivity changes induced by cobalt carbide, very few studies have compared selectivities rigorously at the same conversion level. It is thus difficult to differentiate the variations due to conversion level changes and carburization. Besides, in the above-mentioned studies, carburization has either been induced by promotors addition or by $\mathrm{CO}$ treatment. The use of promotors could affect the catalysts performances intrinsically, making the link between carburization and the selectivity shift not straightforward. CO treatment is thus an interesting strategy to avoid this issue, but it is here again important to verify that no other catalyst properties are modified at the same time. For instance, $\mathrm{CO}$ treatments are known to induce carbon deposition under certain conditions [27], and the attribution of performance evolutions to carbide formation is there again speculative if the absence of carbon deposition is not verified.

We propose herein to study the impact of carburization on selectivity in order to determine precisely its involvement in Fischer-Tropsch Co-based catalyst deselectivation. Accelerated aging treatments will be used to decorrelate the carburization phenomenon from the other deactivation mechanisms such as carbon deposition, and we will verify that no other catalyst properties are modified. A particular attention will also be paid to measuring the selectivity at iso-conversion, by gas space velocity adjustments.

\section{Experimental}

\subsection{Catalysts synthesis}

Two cobalt based catalysts were prepared by incipient wetness impregnation of a silica-doped alumina carrier (Siralox5) with an aqueous cobalt nitrate solution. For each catalyst, two successive impregnation steps were employed to reach the desired Co loading of $15 \mathrm{wt} . \%$. The impregnated catalysts were dried and calcined under different conditions in order to obtain two different cobalt particle sizes. A first catalyst (referred as Co-13) was dried in a static oven at $85^{\circ} \mathrm{C}$ for 12 hours, and then calcined $2 \mathrm{~h}$ at $400^{\circ} \mathrm{C}$ (heating ramp of $\left.2.5^{\circ} \mathrm{C} \cdot \mathrm{min}^{-1}\right)$ in fixed bed reactor under an air flow of $2 \mathrm{Nl} \cdot \mathrm{h}^{-1} \cdot \mathrm{g}^{-1}$. The other catalyst $(\mathrm{Co}-18)$ was 
first dried at $85^{\circ} \mathrm{C}$ for 30 minutes in a static oven, and then transferred into a fluidized bed reactor to be dried a second time under an air flow of $0.8 \mathrm{NL} \cdot \mathrm{h}^{-1} \cdot \mathrm{g}^{-1}$ at $100^{\circ} \mathrm{C}$ for 2 hours (heating $\operatorname{ramp} 1.5^{\circ} \mathrm{C} \cdot \mathrm{min}^{-1}$ ). Calcination was finally performed in the same reactor at $400^{\circ} \mathrm{C}$ (heating ramp $5^{\circ} \mathrm{C} \cdot \mathrm{min}^{-1}$ ), for $2 \mathrm{~h}$ with an air flow of $0.8 \mathrm{NL} \cdot \mathrm{h}^{-1} \cdot \mathrm{g}^{-1}$.

\subsection{Catalysts activation and carburization}

Catalyst activation was performed in-situ at $400^{\circ} \mathrm{C}$ for $16 \mathrm{~h}$, under pure hydrogen $\left(1.3-2.0 \mathrm{NL} \cdot \mathrm{h}^{-1} \cdot \mathrm{g}^{-1}\right)$ with a heating ramp of $2^{\circ} \mathrm{C} \cdot \mathrm{min}^{-1}$. The catalysts were stabilized for $24 \mathrm{~h}$ under syngas, to obtain a rather stable activity with time on stream. This stabilization was carried out for $24 \mathrm{~h}$ using a syngas GHSV in the range $6.7-11.6 \mathrm{NL} \cdot \mathrm{h}^{-1} \cdot \mathrm{g}^{-1}$, at $220^{\circ} \mathrm{C}, \mathrm{H}_{2} / \mathrm{CO}=2.12$ and 20 barg (except for in-situ characterization experiments where atmospheric pressure was used due to reactor design limitations, see section 2.3).

Carburization under syngas is a very slow process, and the amount of cobalt carbide formed during shorttime Fischer-Tropsch tests is small [13]. For instance, Claeys et al. measured a fraction of only $6 \% \mathrm{of}_{2} \mathrm{C}$ after 6 months of Fischer-Tropsch synthesis [15]. In this study, the phenomenon was therefore simulated through a $\mathrm{CO}$ treatment to accelerate the aging process. Cobalt carbide can be formed from metallic cobalt by the Boudouard reaction followed by a carburization step according [28] to:

$$
2 \mathrm{CO}+2 \mathrm{Co}=\mathrm{Co}_{2} \mathrm{C}+\mathrm{CO}_{2} \quad(\text { Eq. } 1)
$$

The accelerated carburization treatment consisted of exposing the catalyst to a $\mathrm{CO} / \mathrm{Ar}$ mixture for $8 \mathrm{~h}$ after stabilization at atmospheric pressure. This procedure was operated at $220^{\circ} \mathrm{C}$ or $230^{\circ} \mathrm{C}$ to vary the amount of cobalt carbide. Depressurisation was carried out after stabilisation under an inert flow before starting the treatments. The treatment temperatures were chosen below $250^{\circ} \mathrm{C}$ since it has been shown that higher temperatures may lead to the formation of other carbon species [27] such as polymeric carbon and graphene $[9,29]$, which are not desired in this study. For these treatments, a mixture of inert gas and $\mathrm{CO}$ at high gas velocity was used $\left(0.48 \mathrm{CO} / 0.52 \mathrm{Ar}\right.$ at $\left.6.4-11.2 \mathrm{NL} \cdot \mathrm{h}^{-1} \cdot \mathrm{g}^{-1}\right)$, to dilute as much as possible the $\mathrm{CO}_{2}$ produced in order not to affect the extent of carburization due to product inhibition. The treatments have also been reproduced on non-stabilized catalysts for TEM analysis due to the sensitiveness of the technique to the presence of waxes.

\subsection{Characterization}

Catalysts specific surface area and pore volume were characterized using nitrogen physisorption. Experiments were carried out over calcined catalysts, with an Asap ${ }^{\circledR} 2420$ instrument from Micromeritics ${ }^{\circledR}$. Specific surface area was deduced from the BET method while pore volume was assimilated to the nitrogen volume adsorbed at maximal pressure.

X-Ray diffractograms of the two calcined catalysts were recorded to determine the cobalt oxide $\left(\mathrm{Co}_{3} \mathrm{O}_{4}\right)$ particle sizes using the Scherrer method. The corresponding metallic cobalt particle sizes were then deduced considering the molar volume ratio of Co over that of $\mathrm{Co}_{3} \mathrm{O}_{4}$ (0.796). A PANalytical X'Pert Pro® apparatus equipped with a copper source $\left(\lambda_{\mathrm{K} \alpha 1}=1.5406 \AA\right)$ was used for analyses. Reduced and carburized catalysts 
diffractograms were also acquired to characterize the catalysts phases at different stages of treatment. Particles size evolution was monitored using Transmission Electron Microscopy (TEM). Dark field images of reduced and reduced-carburized catalysts were taken with a JEM $2100 \mathrm{~F}$ microscope, and average particle sizes were calculated based on 200 particles by fitting a log normal law for the particles size distribution in volume. The volume-averaged particle size $(\mathrm{nm})$ (volume pondered) was calculated as:

$$
\overline{d_{V}}=\frac{\sum_{i=1}^{n} n_{i} d_{i}^{4}}{\sum_{i=1}^{n} n_{i} d_{i}^{3}}
$$

Catalyst fraction of metallic cobalt was estimated by magnetization measurements. It is known that that metallic cobalt exhibits a high magnetic susceptibility compared to its oxide or carbide phases [15,30-33]. Thus, by neglecting the non-metallic cobalt phases magnetization, the fraction of metallic cobalt $\mathrm{Co}^{0} / \mathrm{Co}^{\text {tot }}$ can be estimated according to the following relation:

$$
C o^{0} / C o^{t o t}=\frac{\mathrm{M}_{s}}{\mathrm{M}_{s, \max }}=\frac{\mathrm{M}_{s}}{\sigma \cdot \mathrm{m}}
$$

with $\mathrm{M}_{S}$ the measured saturation magnetization (emu) and $\mathrm{M}_{s, \max }$ the theoretical saturation magnetization for a completely reduced sample, estimated from $\sigma$ the magnetic susceptibility of metallic cobalt $\left(\mathrm{emu}^{\circ} \mathrm{g}^{-1}\right)$, and $\mathrm{m}$ the cobalt mass contained in the sample $(\mathrm{g})$. Saturation magnetization was assimilated to the magnetization measured under a magnetic field of $2 \mathrm{~T}$. Magnetization measurements can also be used to characterize the overall particle size of a given sample. The ferromagnetic fraction, which corresponds to the fraction of metallic particles with a diameter higher than a critical diameter (15-20 nm [34]), can be calculated according to the equation:

$$
\gamma=2 \cdot \frac{\mathrm{M}_{r}}{\mathrm{M}_{s}}
$$

$\mathrm{M}_{r}$ being the remanent magnetization (i.e. magnetization at $0 \mathrm{~T}$ field) and $\mathrm{M}_{s}$ the saturation magnetization. In practice, remanent magnetization was estimated by extrapolating the magnetization profile in function of the magnetic field, measured between $-0.05 \mathrm{~T}$ and $0.05 \mathrm{~T}$.

In-situ methods were also used to investigate the carburization phenomenon while avoiding air exposure. A magnetization monitoring was used to follow the catalysts fraction of metallic cobalt evolution during stabilization, CO treatment and syngas re-exposure, using a $5 \mathrm{~mm}$ fixed bed reactor placed directly inside the magnetometer setup. $250 \mathrm{mg}$ of catalysts was reduced in-situ $\left(16 \mathrm{~h}\right.$ at $\left.400^{\circ} \mathrm{C}, 1.8 \mathrm{NL} \cdot \mathrm{h}^{-1} \cdot \mathrm{g}^{-1} \mathrm{of} \mathrm{H}_{2}\right)$, after which syngas exposure was carried out for $24 \mathrm{~h}$ at $220^{\circ} \mathrm{C}$, but at atmospheric pressure due to the reactor configuration and with a syngas GHSV of $9.5 \mathrm{NL} \cdot \mathrm{h}^{-1} \cdot \mathrm{g}^{-1}$. CO treatments were finally performed according to the protocol described in section 2.2 with a mixture $0.48 \mathrm{CO} / 0.52 \mathrm{He}$ at a GHSV of $9 \mathrm{NL} \cdot \mathrm{h}^{-1} \cdot \mathrm{g}^{-1}$, followed by syngas re-exposure (under the same conditions as stabilisation).

The surface evolution during stabilization, $\mathrm{CO}$ treatment and syngas re-exposure was also characterized by Diffuse Reflectance Infrared Fourier Transform Spectroscopy (DRIFTS), by monitoring the CO 
adsorption signal. The DRIFTS experiment was performed at ambient pressure, using a high temperature DRIFTS cell with $\mathrm{KBr}$ windows (from Harrick Scientific Corporation) and a Praying Mantis collector assembly. The spectrophotometer used was a Nicolet 6700 (ThermoFischer Scientific) equipped with a liquid- $\mathrm{N}_{2}$ cooled MCT detector. The DRIFT spectra were recorded based on minimum 16 scans accumulation, with a resolution of $4 \mathrm{~cm}^{-1} .70 \mathrm{mg}$ of catalyst was used for the experiments. Reduction was carried out under $4.0 \mathrm{NL} \cdot \mathrm{h}^{-1}$ of $0.25 \mathrm{H}_{2} / 0.75 \mathrm{~N}_{2}$, stabilization and syngas re-exposure under $0.9 \mathrm{NL} \cdot \mathrm{h}^{-1}$ of syngas and $\mathrm{CO}$ treatment under $0.3 \mathrm{NL} \cdot \mathrm{h}^{-1}$ of CO diluted in $0.9 \mathrm{NL} \cdot \mathrm{h}^{-1}$ of He. The contribution of gas-phase $\mathrm{CO}$ was subtracted using a $\mathrm{CO}(\mathrm{g})$ spectrum collected at reaction temperature over $\mathrm{KBr}$. To determine the number of adsorption modes contributing to the DRIFTS signal, the signal was modeled by a sum of Gaussian peaks. The quality of the fit, expressed as the residual sum of squares, steadily decreased by the sequential addition of a Gaussian peak up to a total of 5 Gaussian peaks. Further addition of Gaussian peaks did not lower the residual sum of squares any longer. Therefore, the DRIFT signal was described by five different adsorption modes.

Finally, Temperature Programmed Hydrogenation (TPH) analysis was conducted after treatments carried out in a $4 \mathrm{~mm}$ ID quartz reactor to characterize the formed carbon species during treatments based on their hydrogenation temperature, without catalyst unloading. The same gas compositions and flowrates as for magnetization experiments were used for the reduction and treatments. Methane production was monitored through the $\mathrm{m} / \mathrm{z}=15$ signal while heating the sample from $150^{\circ} \mathrm{C}$ to $600^{\circ} \mathrm{C}$ at $5^{\circ} \mathrm{C} \cdot \mathrm{min}^{-1}$, under $0.6 \mathrm{NL} \cdot \mathrm{h}^{-1}$ of $\mathrm{H}_{2}$. In order to determine the amount and nature of carbon species after FTS, aa experiment was carried out where the fresh catalyst was exposed to a $\mathrm{H}_{2} / \mathrm{CO}$ mixture at $220^{\circ} \mathrm{C}$ and 1 bar in the TPH reactor. At the end of the run, the gas mixture was switched to argon, the reaction temperature was lowered to room temperature and the THP experiments was carried out.

\subsection{Fischer-Tropsch experiments}

Catalyst performances were evaluated before and after carburization using a High Throughput Experimentation (HTE) setup, developed by the Avantium company. The unit is structured by sixteen fixed bed reactors ( $2 \mathrm{~mm}$ ID) running in parallel, but with a mutual gas feed, equally distributed over all 16 reactors by means of a patented micro-chip. A more complete description of the unit and performance calculations can be found in a previous publication [35].

For fresh catalyst testing, $350 \mathrm{mg}$ of oxide catalyst was reduced according to the protocol described in section 2.2 with a $\mathrm{H}_{2}$ GHSV of $1.8 \mathrm{NL} \cdot \mathrm{h}^{-1} \cdot \mathrm{g}^{-1}$, followed by a decrease of the temperature to $180^{\circ} \mathrm{C}$ under hydrogen and the pressure progressively raised to $20 \mathrm{barg}$. Syngas was finally injected with a flowrate of $2.51 \mathrm{NL} \cdot \mathrm{h}^{-1}$ containing $5 \% \mathrm{He}$ and the temperature was increased to $220^{\circ} \mathrm{C}$ (by a ramp of $1^{\circ} \mathrm{C} \cdot \mathrm{min}^{-1}$ ). After $24 \mathrm{~h}$ of stabilization, the flowrate was varied to measure the product distribution at different conversion levels. 
For carburized catalyst testing, the same initial procedure was applied except that after stabilization, the pressure was decreased to $1 \mathrm{bar}$ under inert flow and catalysts were treated under a $0.48 \mathrm{CO} / 0.42 \mathrm{~N}_{2} / 0.10$ He flow of $2.25 \mathrm{NL} \cdot \mathrm{h}^{-1}$ for $8 \mathrm{~h}$. Syngas was subsequently re-introduced while the pressure was increased to 20 barg and the temperature decreased to $220^{\circ} \mathrm{C}$, and the gas flowrate was varied to measure the product distribution at different conversion levels.

The catalyst activity was noted $\mathrm{r}_{C O}\left(\right.$ in $\left.\mu \mathrm{mol} \cdot \mathrm{s}^{-1} \cdot \mathrm{g}^{-1}\right)$ and calculated as:

$$
\mathrm{r}_{C O}=\frac{\mathrm{X}_{C O} \cdot \mathrm{Q}_{C O, \text { in }}}{V_{m, C O} \cdot m_{\text {catalyst }}}
$$

with $V_{m, C O}$ the $\mathrm{CO}$ molar volume under standard conditions of temperature and pressure and $\mathrm{Q}_{C O \text {,in }}$ the $\mathrm{CO}$ inlet flowrate $\left(\mathrm{sL} \mathrm{s}^{-1}\right)$. We observed a linear increase of the $\mathrm{CO}$ conversion with increasing catalyst mass up to a conversion of $60 \%$, which indicates that the reaction order in $\mathrm{CO}$ is approximately zero.

\subsection{Wax composition analysis}

The liquid product fraction collected during high-throughput tests was analysed ex-situ by simulated distillation to estimate the chain growth probability of heavy compounds (typically $\mathrm{C}_{17+}$ hydrocarbons). The liquid samples were dissolved in $\mathrm{CS}_{2}$ before being eluted through a MXT®-1 column, and hydrocarbons were quantified with a Flame Ionization Detector. The chain growth probability $\alpha$ was calculated by fitting the Anderson-Schulz-Flory (ASF) equation [36] to the $\mathrm{C}_{17-42}$ hydrocarbons distribution.

\section{Results}

\subsection{Catalysts physical properties}

Table 1: Catalysts textural properties and particles size.

\begin{tabular}{lllll}
\hline & $\begin{array}{l}\mathrm{S}_{\mathrm{BET}} \\
\left(\mathrm{m}^{2} / \mathrm{g}\right)\end{array}$ & $\begin{array}{l}\mathrm{V}_{\mathrm{p}} \\
(\mathrm{ml} / \mathrm{g})\end{array}$ & $\begin{array}{l}\mathrm{d}_{\mathrm{Co} 3 \mathrm{O} 4, \mathrm{XRD}} \\
(\mathrm{nm})\end{array}$ & $\begin{array}{l}\mathrm{d}_{\mathrm{Co}, \mathrm{XRD}} \\
(\mathrm{nm})\end{array}$ \\
\hline $\mathrm{Co}-13$ & 133 & 0.36 & $13 \pm 1$ & $10 \pm 0.8$ \\
$\mathrm{Co}-18$ & 135 & 0.36 & $18 \pm 2$ & $14 \pm 1.6$ \\
\hline
\end{tabular}

Oxide catalyst surface areas and pore volumes are presented in Table 1. No major difference is observed between the two catalysts, which both exhibit slightly lower surface area and pore volume than the support $\left(171 \mathrm{~m}^{2} \cdot \mathrm{g}^{-1}, 0.52 \mathrm{~mL} \cdot \mathrm{g}^{-1}\right)$. Some have attributed this phenomenon to pore blockage by cobalt oxide particles [37], but in our case it also corresponds to a large part to the addition of cobalt that decreases the mass fraction of the support in the final catalyst, thus decreasing the apparent specific surface area and porosity.

The average particle sizes of the two catalysts given by XRD are also reported in Table 1 . The Co- 18 catalyst shows a larger particle size than the Co-13 one, with an average value of $18 \mathrm{~nm}$ against $13 \mathrm{~nm}$. 
Considering the molar volumes of $\mathrm{Co}^{0}$ and $\mathrm{Co}_{3} \mathrm{O}_{4}\left(\mathrm{v}_{\mathrm{Co}} / \mathrm{v}_{\mathrm{Co} 3 \mathrm{O} 4}=0.796\right)$, the average particles sizes of the catalysts in the reduced state are thus estimated to be $10 \mathrm{~nm}$ and $14 \mathrm{~nm}$.

\subsection{Investigation of cobalt carbide formation under $\mathrm{CO}$ atmosphere}

\subsubsection{X-ray diffraction}

To study the phase transformations occurring during catalyst stabilization, CO treatments and syngas reexposures, XRD analysis was carried out with representative samples treated in the HTE unit. Even if waxes produced during stabilisation should prevent the samples from air-induced re-oxidation, the samples were also unloaded under inert atmosphere $\left(\mathrm{O}_{2}<0.5 \mathrm{ppm}, \mathrm{H}_{2} \mathrm{O}<0.5 \mathrm{ppm}\right)$. Figure 1a shows the diffractograms obtained over Co-18 samples prepared according to the protocol described in section 2.2, and Figure $1 \mathrm{~b}$ those obtained over $\mathrm{Co}-13$. After reduction, both $f c c-\mathrm{Co}^{0}$ phase and $\mathrm{CoO}$ phases are detected, indicating a partial reduction of the catalysts. However, during syngas stabilisation, the $\mathrm{Co}^{0}$ diffraction line increases, which indicates a further reduction of the catalyst under syngas, as reported in several studies [38-41]. After subsequent carburization at $220^{\circ} \mathrm{C}$ or $230^{\circ} \mathrm{C}$ for $8 \mathrm{~h}$, the signal at $42.7^{\circ}$ is significantly increased and is assigned to cobalt carbide formation. Indeed, the $\mathrm{Co}_{2} \mathrm{C}$ secondary diffraction lines are also detected at $41.3^{\circ}$ and $56.6^{\circ}$, whereas no significant $\mathrm{CoO}$ diffraction line evolutions are observed. These results confirm the formation of a cobalt carbide phase under $\mathrm{CO}$ atmosphere, which is most probably formed from metallic cobalt and carbon formed from the Boudouard reaction (Eq.1). Besides, the carbide signal increase is higher with the $230^{\circ} \mathrm{C}$ treatment than with the $220^{\circ} \mathrm{C}$ one, which reveals a higher extent of carburization at high temperature. It was not possible to estimate the size of the carbide domains from the XRD data, due to the low signal. 

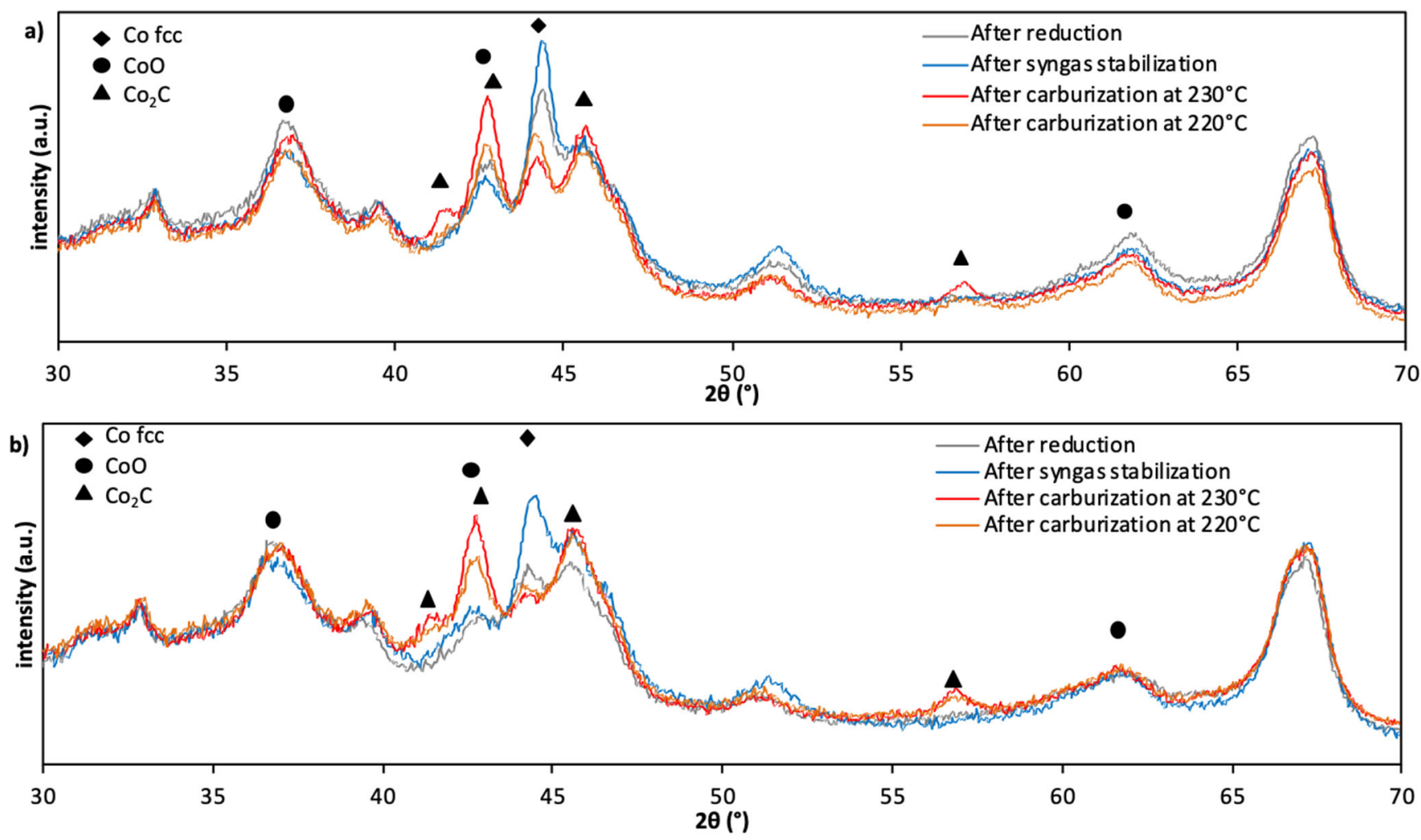

Figure 1: Diffractogramms of the Co-18 (a) and Co-13 (b) catalysts treated in the HTE test unit and unloaded under inert atmosphere.

\subsubsection{Magnetization measurements}

Since the phase modifications are difficult to quantify by XRD and because there are some uncertainties in the XANES fit, magnetization measurements were carried out for quantitative analysis. A first series of in-situ experiments has been performed in order to better understand the carburization process. Figure 2 shows the evolution of $M_{S} / M_{s, \max }$ and ferromagnetic fraction of the Co-18 catalyst measured in-situ during the stabilization, the two $\mathrm{CO}$ treatments at $220^{\circ} \mathrm{C}-230^{\circ} \mathrm{C}$ and subsequent syngas re-exposure. For each experiment, the very first and last measurements were recorded at room temperature under pure argon, to avoid any temperature and chemical effect on the magnetization response. When inert gas is initially replaced by syngas an important decrease of both $M_{s} / M_{s, \max }$ and ferromagnetic fraction are recorded, due to the adsorption of $\mathrm{H}_{2}$ and $\mathrm{CO}$ at the catalyst surface known to reduce the magnetization response $[42,43]$. During the subsequent $24 \mathrm{~h}$ of syngas exposure no further change is detected, indicating a stable fraction of metallic cobalt and particles size. When syngas is switched to $\mathrm{CO} / \mathrm{Ar}$ mixture, two distinct periods can be observed: a first phase of fast $M_{S} / M_{s, \max }$ and ferromagnetic fraction decay followed by a slower one. The first phase may correspond to the formation of a carbide shell at the catalysts surface, whereas the second one to the formation of bulk cobalt carbide. For this type of carbide, carbon atoms have indeed to diffuse through the first atomic layers of particles, making its formation slower than surface carbide [44]. Based on DFT calculations, $\mathrm{Li}$ et al. [44] even suggested that vacancies were required for carbon to diffuse into the bulk and thus form bulk cobalt carbide. This "shrinking core" model is supported by the rapid decrease of the 
ferromagnetic fraction along with $M_{s} / M_{s, \max }$, which indicates that the ferromagnetic domains are becoming smaller during the $\mathrm{CO}$ treatments. Preferential carburization of big particles could also explain this behaviour, it will therefore be investigated by TEM.
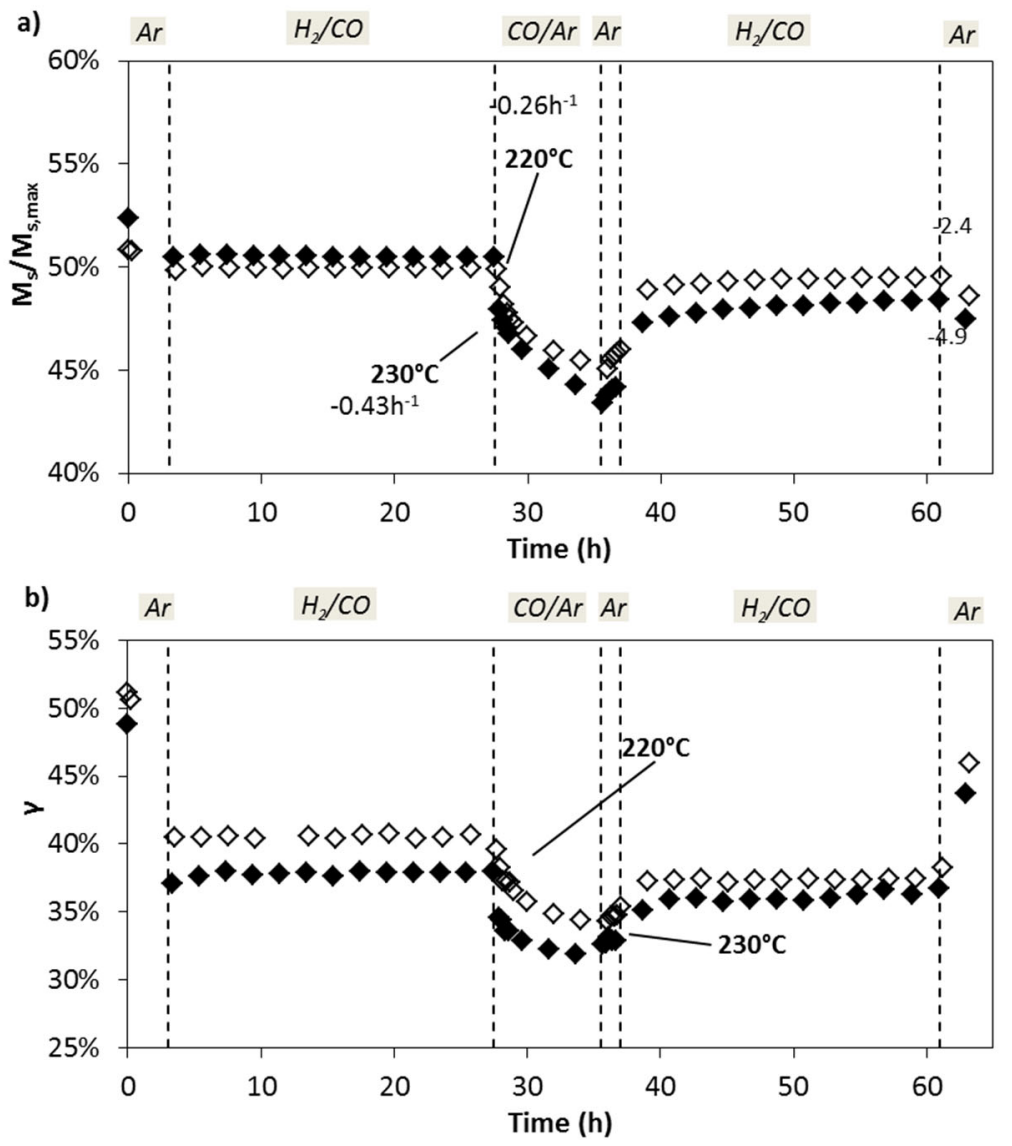

Figure 2: Evolution of saturation magnetization (a) and ferroelectric fraction (b) of Co-18 catalyst during initial syngas exposure at $\mathrm{P}_{\text {atm }}\left(\mathrm{H}_{2} / \mathrm{CO}=2\right)$, $\mathrm{CO}$ treatments and subsequent syngas exposure.

After the $\mathrm{CO}$ treatment, the catalysts were exposed to argon for $1 \mathrm{~h}$ at $220^{\circ} \mathrm{C}$ before being exposed to syngas again. An increase of both $M_{s} / M_{s, \max }$ and ferromagnetic fraction is observed during this period, indicating most probably decarburization of the catalyst surface. The first hours of the subsequent syngas exposure also lead to an increase of these two parameters, which is again associated with re-reduction of the catalysts. However, after 2-4 hours the magnetization reached a relatively stable value, lower than the value measured before carburization indicating the formation of a stable cobalt carbide phase.

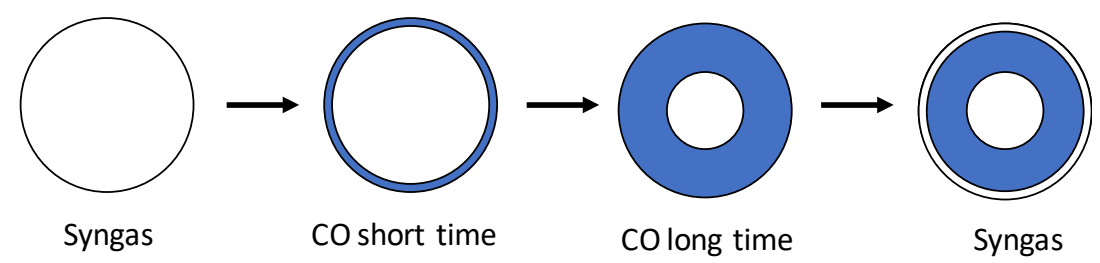

Figure 3: Schematic representation of the catalyst during stabilization (left), carburization (centre) and syngas re-exposure (right). Dark regions correspond to carbidic cobalt phase, and the rest to metallic cobalt phase. 
Claeys et al. [15] also observed this two-step carbide decomposition when a $\mathrm{CO}$ treated $\mathrm{Co}-\mathrm{Pt} / \mathrm{Al}_{2} \mathrm{O}_{3}$ catalyst was exposed to syngas. The authors proposed that decarburization proceeds in the same way that carburization does according to the present results, via a core-shell model. The first phase corresponds to the decomposition of surface carbide, which leads to the formation of a metallic cobalt shell. Bulk cobalt carbide is therefore protected from hydrogen, which results in a much slower decomposition.

A schematic view of the overall process is illustrated on Figure 3, from the left to the right. The metallic catalyst surface is first changed to carbidic surface right after removal of hydrogen from the feed (early stage of $\mathrm{CO}$ treatment), then carbon atoms produced by $\mathrm{CO}$ disproportionation diffuse into the cobalt particles to form the $\mathrm{Co}_{2} \mathrm{C}$ phase. Structural changes are moreover occurring at the same time, since metallic cobalt is, according to XRD results, mainly in the cubic form while $\mathrm{Co}_{2} \mathrm{C}$ has a hexagonal structure. When hydrogen is introduced again (i.e. syngas re-exposure), the bulk cobalt carbide remains stable but the surface is cleaned from atomic carbon or surface carbide. In the case where the particle has not been entirely carburized, it might still have a metallic core but with a carbide layer around, and another metallic layer on the surface. A possible alternative explanation that cannot be excluded is that the carbon vacancy is randomly distributed in the lattice of Co carbide or carbon is randomly distributed in Co lattice.

It is finally important to note that the treatment temperature affects the carburization rate. The slope of the $M_{S} / M_{s, \max }$ decay is more important during the $230^{\circ} \mathrm{C} \mathrm{CO}$ treatment than the $220^{\circ} \mathrm{C}$ treatment, indicating a faster phase transformation at high temperature. This explains why a higher extent of carburization was found by XRD on the $230^{\circ} \mathrm{C}$ treated samples, compared to $220^{\circ} \mathrm{C}$ treated ones. It is therefore possible to control the amount of cobalt carbide $\left(\mathrm{Co}_{2} \mathrm{C}\right)$ formed for a given treatment duration, by adjusting the treatment temperature.

Ex-situ magnetization measurements have been performed on samples treated directly in the HTE setup, to estimate the degree of carburization (DOC) of the catalysts to be tested in FTS. The degree of carburization is assumed to be equal to the fraction of metallic cobalt loss with respect to the stabilized catalyst. As mentioned in section $2.4,350 \mathrm{mg}$ of the two catalysts were reduced under $0.45 \mathrm{NL} \cdot \mathrm{h}^{-1}$ of $\mathrm{H}_{2}$ and stabilized $24 \mathrm{~h}$ under syngas. Those were subsequently carburized at $220^{\circ} \mathrm{C}$ and $230^{\circ} \mathrm{C}$, and the reactors were cooled down under a $\mathrm{N}_{2}$ flow before unloading the catalysts under inert atmosphere. Reduced and stabilized samples were also prepared as reference, using the same conditions.

The degree of carburization shown together with the metallic cobalt losses from magnetization measurements are shown in Table 2. Despite a different particle size, the two catalysts present initially a similar degree of reduction. After carburization, both catalysts lose a significant amount of metallic cobalt which is associated with the carbide formation through the Boudouard reaction (Eq. 1). As concluded from in-situ experiments, a significant impact of the treatment temperature is observed on the extent of carburization. The catalysts are globally $25 \%$ more carburized after a $230^{\circ} \mathrm{C}$ treatment than a $220^{\circ} \mathrm{C}$ one. 
Besides, the Co-13 catalyst appears to be more carburized than the Co-18 catalyst, indicating a particle size effect on the carburization sensitivity. This behaviour might be linked to the core-shell mechanism, for which a highly dispersed material will be carburized faster than a poorly dispersed one. Braconnier et al. [45] observed no effect of particles size on carburization. However, they compared catalysts with different initial degree of reduction. In particular, their "small particle catalyst" was less reduced than the big particles one, which might result in a slower carburization (via the Boudouard reaction).

Table 2: Fraction of metallic cobalt and degree of carburization (DOC) of catalysts treated in the HTE setup

\begin{tabular}{lll}
\hline & $\mathrm{Co}^{0} / \mathrm{Co}^{\text {tot }}$ & $\mathrm{DOC}^{\mathrm{a}}$ \\
\hline $\mathrm{Co}-13$ & $54 \%$ & - \\
$\mathrm{Co}-13220^{\circ} \mathrm{C}$ CO treated & $34 \%$ & $45 \%$ \\
Co-13 $230^{\circ} \mathrm{C}$ CO treated & $25 \%$ & $57 \%$ \\
& & \\
$\mathrm{Co}-18$ & $54 \%$ & - \\
$\mathrm{Co}-18220^{\circ} \mathrm{C} \mathrm{CO}$ treated & $38 \%$ & $37 \%$ \\
$\mathrm{Co}-18230^{\circ} \mathrm{C} \mathrm{CO}$ treated & $27 \%$ & $48 \%$ \\
\hline \multicolumn{2}{c}{${ }^{\mathrm{a}}$ considering the Boudouard reaction only }
\end{tabular}

\subsubsection{TEM}

To verify that the higher extent of carburization of the Co-13 catalyst is not due to preferential carburization of small particles, dark field TEM images were taken on Co-18 catalyst after reduction and carburization at $230^{\circ} \mathrm{C}$ in the HTE setup. The obtained size distributions (volume pondered) showed that the $\mathrm{Co}^{0}$ particles size was not altered by the treatments (Figure 4). We can thus conclude that no preferential carburization of particles of a certain size occurs under $\mathrm{CO}$ atmosphere. Besides, this observation also indicates that no sintering is induced by the treatment, which could have been the case according to the sintering mechanism via carbonyl formation [46].

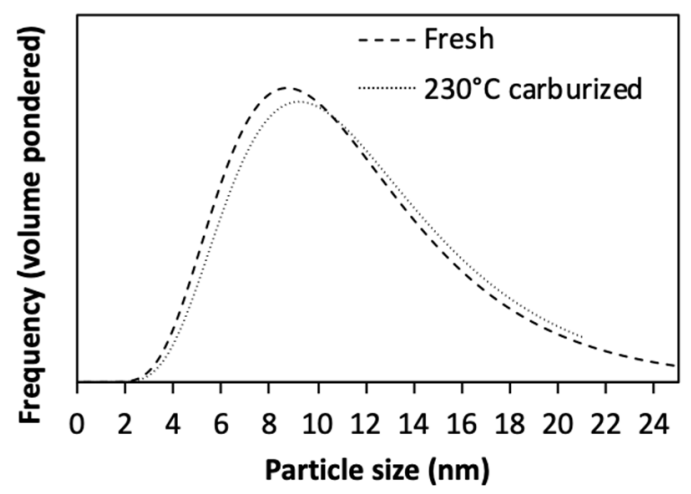

Figure 4: Particles size distribution of the Co-18 catalyst before and after $\mathrm{CO}$ treatment at $230^{\circ} \mathrm{C}$, by $\mathrm{TEM}$ (volume pondered)

\subsubsection{TPH}

As mentioned previously, temperature is an important parameter regarding the carbon species which are formed during $\mathrm{CO}$ treatments. A too high temperature do not only carburize metallic cobalt, but also generate 
carbon deposition at the catalyst surface [27]. TPH experiments were carried out after treatments to verify that cobalt carbide was the only formed carbon species. The obtained profiles for the Co-18 catalyst are presented in Figure 5, together with the profile of the syngas exposed Co-18 catalyst as a reference. On this profile, most of the detected carbon compounds are hydrogenated around $200^{\circ} \mathrm{C}$, which might correspond either to hydrogenation temperature of surface carbide $[9,11]$ or hydrocarbons adsorbed at the catalyst surface [9]. After the $220^{\circ} \mathrm{C} \mathrm{CO} /$ inert treatment, this main peak is considerably reduced but a new one appears at $230^{\circ} \mathrm{C}$. This new peak is even shifted to $250^{\circ} \mathrm{C}$ for the $230^{\circ} \mathrm{C}$ treatment. These two peaks are this time associated with bulk cobalt carbide $[11,15]$, which is for the $230^{\circ} \mathrm{C}$ treated catalyst more difficult to reduce probably because of a bulkier phase. Carbon compounds are also detected from $250^{\circ} \mathrm{C}$ to $500^{\circ} \mathrm{C}$ but in a very low amount. We conclude from these data that only small amounts of polymeric carbon (i.e. coke) was significantly deposited during the $\mathrm{CO}$ treatments.

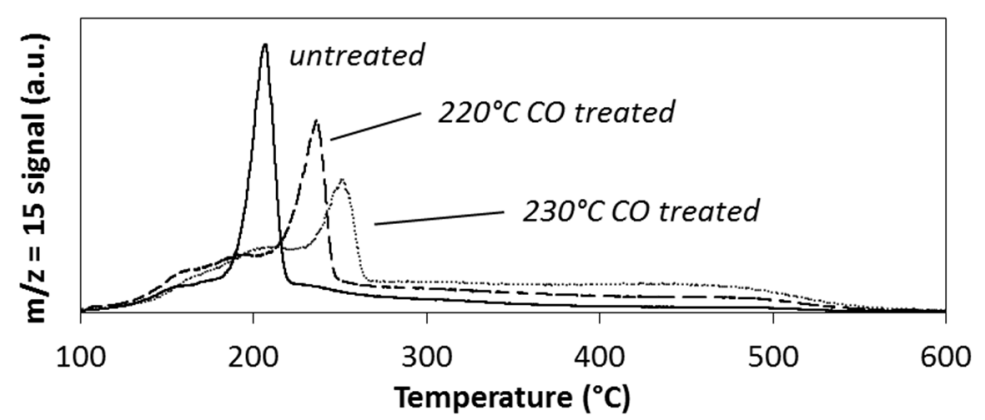

Figure 5: TPH profile of syngas exposed and syngas exposed/CO treated Co-18 catalyst. 

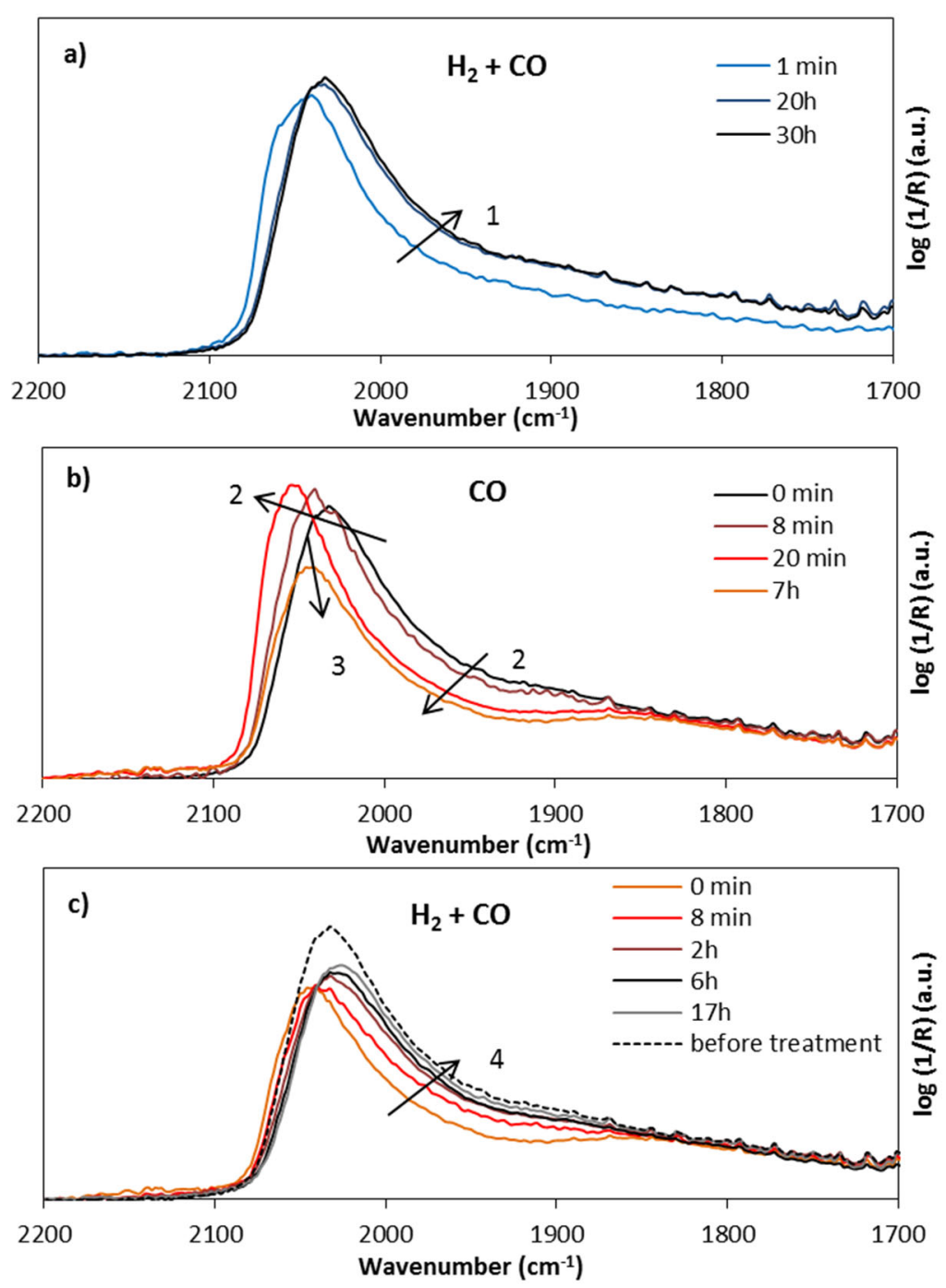

Figure 6: Co-18 catalyst DRIFTS signal evolution in the CO adsorption region during a) syngas stabilization, b) $\mathrm{CO}$ treatment and c) syngas re-exposure. $\mathrm{T}=220^{\circ} \mathrm{C}$.

DRIFTS is a powerful technique to characterize the catalyst surface in situ or even operando through the adsorption of suitable molecules. CO, one of the reactants of the Fischer-Tropsch synthesis and a common probe molecule in IR, is thus an ideal means to characterize the surface of Fischer-Tropsch catalysts under relevant reaction conditions $[47,48]$.

The Co-18 catalyst surface was monitored by DRIFTS during the syngas stabilization, carburization at $220^{\circ} \mathrm{C}$ and syngas re-exposure, all at atmospheric pressure. Figure 6 presents the DRIFTS intensity evolution (reported as pseudo-absorbance $\log (1 / \mathrm{R}), \mathrm{R}$ being the reflectance) in the $2200-1700 \mathrm{~cm}^{-1}$ region during these three steps (respectively a, b and c). When the reduced catalyst is first exposed to syngas, two modes of CO adsorption are detected already after $1 \mathrm{~min}$, i.e. the linear [49-52] CO adsorption between $2000-2100 \mathrm{~cm}^{-}$ ${ }^{1}$ and the bridged or multi-bonded [49-52] CO adsorption between $1700-2000 \mathrm{~cm}^{-1}$. During the first hours of syngas exposure, the signal is shifted towards lower wavenumbers and the multi-bonded adsorbed $\mathrm{CO}$ signal increases. This can be explained by surface reconstruction $[53,54]$ that increases the surface roughness 
[55] and increases the electronic donation from cobalt into the $\mathrm{CO} 2 \pi^{*}$ anti-bonding orbital, thereby lowering the wavenumber of the $\mathrm{CO}$ stretching vibration and increasing the concentration of adsorbed CO. Further reduction of the catalyst, as observed by $\mathrm{XRD}$ is also a plausible explanation, during which very small oxide particles in strong interaction with the support would get reduced, exhibiting a more defective surface [49]. After $20 \mathrm{~h}$ no further evolution of the signal was detected, which indicates a stabilized catalyst.

After $30 \mathrm{~h}$ of syngas exposure the hydrogen feed was stopped to start the CO-only treatment. The signal acquired just before the switch was deconvoluted as shown in Figure $7 \mathrm{a}$, and an adequate fit was obtained with five Gaussian peaks assumed to correspond to five adsorption modes. This is of course an approximation, as each particle size would lead to a somewhat different spectrum, even for similar particle shapes. The first two species at 2047 and $2026 \mathrm{~cm}^{-1}$ are assigned to linear [49-52] CO adsorbed on planar surfaces most probably the (111) and the (100) facets, respectively [47]. The other bands are tentatively assigned to bridged CO adsorbed on step $B_{5}$ sites [17] (A and B types, at 1994 and $1931 \mathrm{~cm}^{-1}$ ) and multibonded $\mathrm{CO}$ adsorbed on defects $\left(\mathrm{B}_{6}\right.$ sites, at $\left.1813 \mathrm{~cm}^{-1}\right)$. A representation of these sites can be found in $\mathrm{Ge}$ et al. [56].
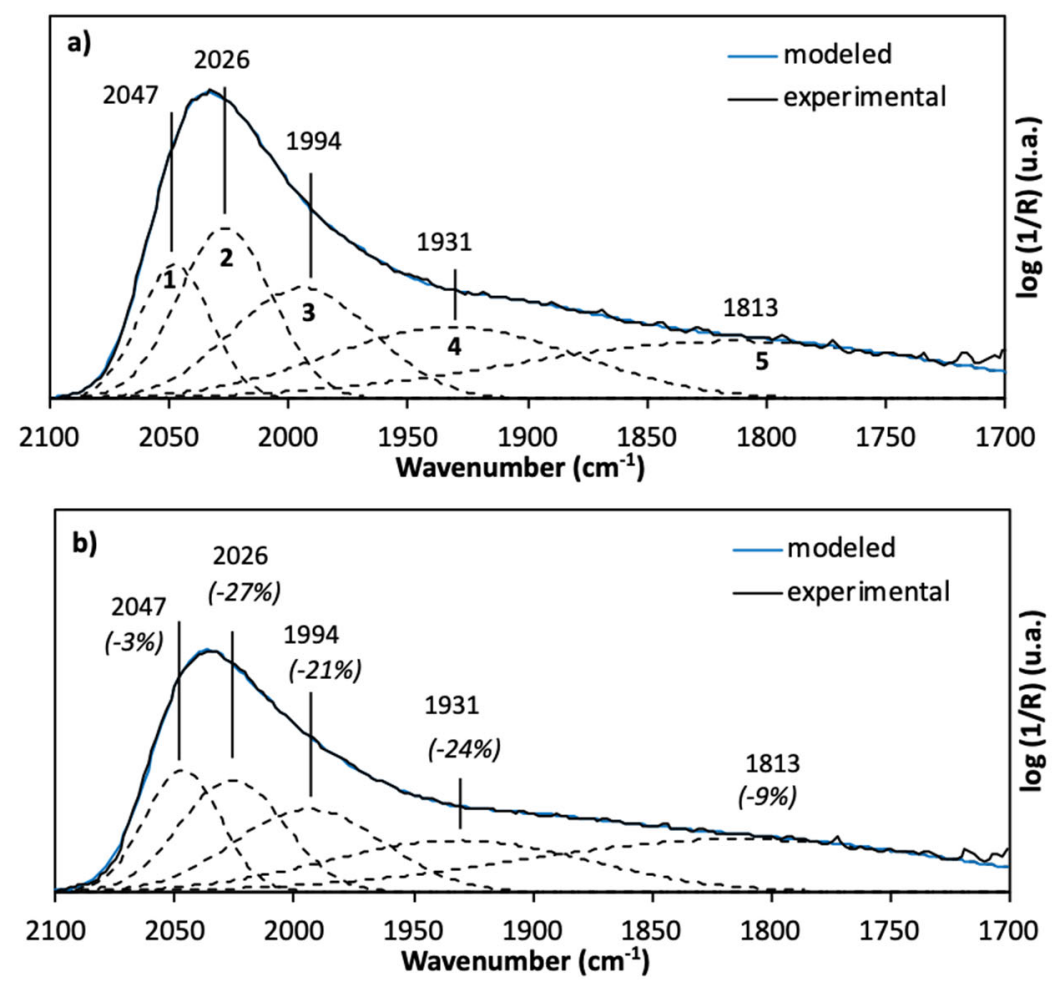

Figure 7: Deconvolution of the Co-18 catalyst DRIFTS signals in the carbonyl region a) after 30h stabilization under syngas, b) subsquently after $17 \mathrm{~h}$ of syngas re-exposure following treatment under $\mathrm{CO}$ for $8 \mathrm{~h}$. Number in brackets show the area loss of the deconvoluted peaks relatively to the $30 \mathrm{~h}$ syngas stabilized Co-18 catalyst signal shown in (a). $\mathrm{T}=220^{\circ} \mathrm{C}$.

After the switch to pure $\mathrm{CO}$, the signal starts to evolve again and two periods can be distinguished. In the first $20 \mathrm{~min}$ (Figure 6b, arrows noted " 2 ") the linear CO bands (above $2000 \mathrm{~cm}^{-1}$ ) shifted towards higher wavenumbers, while the signal between 2000 and $1850 \mathrm{~cm}^{-1}$ dropped. These observations can be rationalised as follows. $\mathrm{CO}$ is likely to continue dissociating for a while after $\mathrm{H}_{2}$ was removed from the feed. This would result in the accumulation of $\mathrm{C}$ and $\mathrm{O}$ at the active sites, which were shown to be those associated with 
bridged/multi-bonded CO on a similar catalyst [57]. This explains the drop of the signal below $2000 \mathrm{~cm}^{-1}$, due the replacement of reactive $\mathrm{CO}$ with adsorbed $\mathrm{C}$ and $\mathrm{O}$, most of the latter being eventually removed by $\mathrm{CO}$ to form $\mathrm{CO}_{2}$. The accumulating carbon, which is more electronegative than cobalt, will lower the electronic density in the neighbouring cobalt sites. This will result in turn to less electronic density injected from cobalt to the antibonding orbital of the remaining adsorbed $\mathrm{CO}$, which will exhibit a blue-shift towards higher wavenumbers. Thus, this model also explains the blue shift of the linear CO observed in figure $6 \mathrm{~b}$. Note that linear $\mathrm{CO}$ species were shown to be spectators and should remain undissociated [57].

Such superficial carburization of metallic cobalt has already been proposed by Bianchi et al. [50] and some of us [49] to explain a $\mathrm{CO}(\mathrm{ads})$ blue shift under $\mathrm{H}_{2}$-free $\mathrm{CO}$. This effect can occur at temperatures as low as $154^{\circ} \mathrm{C}$ within minutes, hence it is unlikely to involve the migration of carbon into the bulk of the cobalt metal particles [50]. Such blue shifts have also been reported by Chen et al. [58] on a C- and Ocovered catalyst using $\mathrm{C}_{2} \mathrm{H}_{2}$ and $\mathrm{N}_{2} \mathrm{O}$ pre-treatments. We therefore propose that the initial blue shift of the linear $\mathrm{CO}$ and the decay of multi-bonded $\mathrm{CO}$ (Figure 6.b-arrows 2) observed over the 20 first minutes under $\mathrm{CO}$ at $220^{\circ} \mathrm{C}$ are associated with the formation of adsorbed carbon at the surface of metallic cobalt, without any significant bulk carbide formation.

The spectral changes during the subsequent period under $\mathrm{CO}(20 \mathrm{~min}-7 \mathrm{~h}$, Figure 6b, arrow 3$)$ are significantly slower. The linear CO signal above $2000 \mathrm{~cm}^{-1}$ gradually decreases, exhibiting a red-shift. The origin of this red-shift can be the lowering of dipole coupling due to a lower surface coverage or a modification of the surface/bulk structure. The signal decrease is most likely due to a lowering of the adsorption capacity of the catalyst, which can either be due to carbon poisoning or bulk carbide formation (with an associated enthalpic effect or decrease of surface density of Co atoms). We favour the carbide formation explanation, in view of the XRD and magnetization results.

A new signal evolution is observed when the catalyst is re-exposed to syngas (Figure 6c). The peak evolution pathway is, however, not symmetrical to the one observed during carburization. The peaks shift back directly to the original positions (measured at steady-state under syngas before the $\mathrm{CO}$ treatment), and the overall signal intensity increases, but without recovering the original intensity. No more evolution of the signal is observed after $\sim 2 \mathrm{~h}$ of syngas exposure. The fact that the peaks shift back to their original wavenumbers without passing through the higher wavenumbers indicates that the metallic surface is immediately recovered. This can be rationalised by assuming that the any surface carbon (carbidic and adatoms) is readily removed by $\mathrm{H}_{2}$ and the metallic surface remains $\mathrm{C}$-free [50]. This observation supports the hypothesis of a core-shell model (Figure 3, right) controlling the decarburization process, already mentioned to explain the magnetization increase when $\mathrm{CO}$ is replaced by syngas ( $c f$ section 3.3.2).

The overall DRIFTS signal intensity loss observed after these treatments is therefore attributed to bulk cobalt carbide formation only. Note that the TPH data excluded graphite formation and the TEM analysis did not indicate a loss of cobalt dispersion. The deconvolution of the $17 \mathrm{~h}$ syngas re-exposed catalyst signal (Figure $7 b$ ) shows that every peak intensity is decreased. Since the bridged and multi-bonded adsorption modes are significantly altered by the treatment, a loss of catalytic activity could be expected [47,57]. 
Meunier and co-workers [57] indeed showed that the bridged $\mathrm{CO}$ sites may be the most active ones for $\mathrm{CO}$ dissociation, which has also been corroborated by DFT calculations [17]. It is also interesting to note that despite the fact that signal loss is not equivalent for every adsorbed species, the linear modes and multibonded modes together loss a similar signal fraction (17\% and $18 \%$ respectively).

\subsection{Impact of carburization on catalyst performances}

\subsubsection{Activity}

To evaluate the effect of the $\mathrm{CO}$ treatments on catalyst performances, the $\mathrm{CO}$ consumption rate of the $\mathrm{CO}$ treated catalysts was compared to the fresh catalysts under conventional Fischer-Tropsch conditions $\left(220^{\circ} \mathrm{C}\right.$, 20 barg, $\mathrm{H}_{2} / \mathrm{CO}=2.12$ ). This rate has been evaluated at different syngas GHSV, in order to compare the activity as a function of $\mathrm{CO}$ conversion. CO conversion has indeed not only an effect on selectivity, but also on the reaction rate due to variations of reactant partial pressures, on which this rate depends on [59]. It is thus important to compare rates at iso-conversion to be able to conclude on deactivation.

Co-18

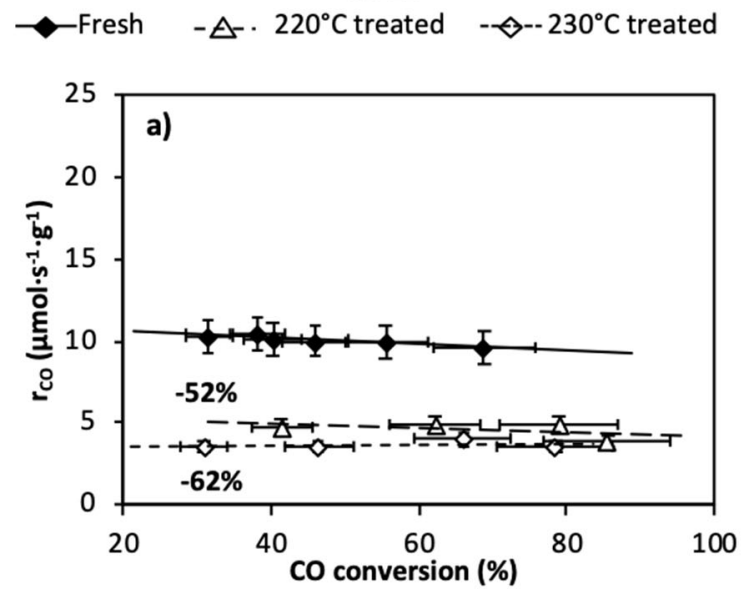

Co-13

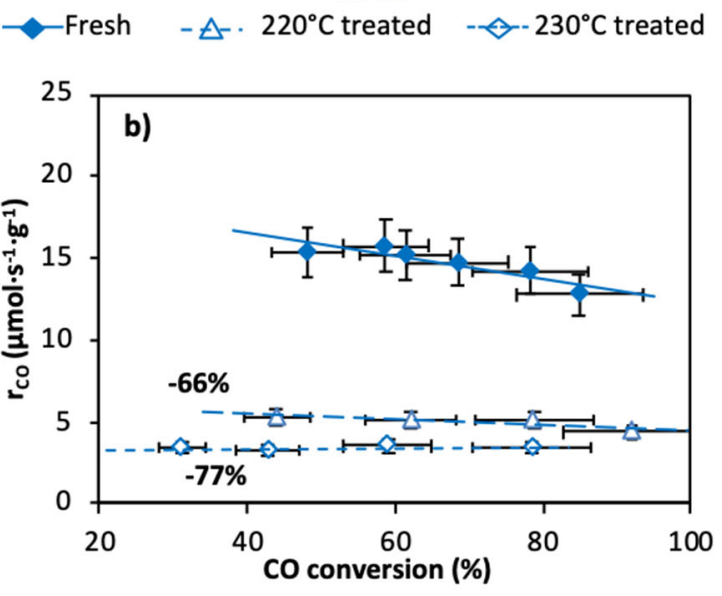

Figure 8: Co-18 (a) and Co-13 (b) catalysts activity as function of the $\mathrm{CO}$ conversion, at $20 \mathrm{barg}, 220^{\circ} \mathrm{C}, \mathrm{H}_{2} / \mathrm{CO}=2.12$. Solid and dashed lines are a guide to the eyes.

Figure 8 presents the obtained $\mathrm{CO}$ consumption of the fresh and $\mathrm{CO}$ treated catalysts, as function of $\mathrm{CO}$ conversion. Firstly, one can observe that the $\mathrm{CO}$ consumption rate is only slightly affected by the $\mathrm{CO}$ conversion level, certainly because the reaction order in $\mathrm{CO}$ is close to zero. The two reduced catalysts do not exhibit the same activity, Co-13 being more active. Because the two catalysts exhibit a similar fraction of metallic cobalt after syngas stabilization (Table 2), the difference in activity is necessarily due to the higher dispersion of Co-13 catalyst.

After the CO treatments, the two catalysts are significantly deactivated, and the extent of deactivation depends on the treatment temperature. The Co- 18 catalyst loses $52 \%$ of its activity after the $220^{\circ} \mathrm{C}$ treatments whereas a decrease of $62 \%$ is observed after the $230^{\circ} \mathrm{C}$ treatment. Moreover, for a similar treatment condition the Co-13 catalyst is more deactivated than the Co-18 one $\left(66 \%\right.$ and $77 \%$ of rate diminution for the $220^{\circ} \mathrm{C}$ and $230^{\circ} \mathrm{C}$ treatments), which can be explained by its higher extent of carburization. Since a core-shell mechanism has been proposed for carburisation and because no sintering was detected after treatments, the 
number of active sites do only change due to carbon deposits, which was found be small on the carburized catalysts. Thus, the observed deactivation might be linked to the modification of the catalysts active site efficiency, induced by the bulk phase transformation. This change in the properties of the active site may also alter the product selectivity, which is discussed hereafter.

\subsubsection{Selectivity}

Figure 9 presents the selectivity for the main Fischer-Tropsch products as function of the CO conversion, under standard conditions (corresponding to the activity measurements shown in Figure 8). As for the activity, the selectivity for the two reduced catalysts is quite similar. This observation may seem contrary to the well-known tendency of the selectivity to increase with cobalt particle size [60-63], but is in line with the conclusions of Bezemer et al. [61] who found no significant effect of particle size above $8 \mathrm{~nm}$. The effect of the contact time (i.e. CO conversion) on catalysts selectivity is also quite similar for both catalysts, and in accordance with the literature [7,64-66]. An increase of $\mathrm{C}_{5+}$ and $\mathrm{CO}_{2}$ selectivity are observed with the increase of $\mathrm{CO}$ conversion, while $\mathrm{CH}_{4}$ and olefin selectivity decrease. Todic et al. [7] discussed the origin of these trends, and explained that the heavy compounds and $\mathrm{CH}_{4}$ selectivity evolution at high conversions were mainly due to water effects $[20,67,68] . \mathrm{CO}_{2}$ production increases at high conversion because of the high partial pressure of water, and the olefin selectivity decline is associated with the longer residence time used to reach high conversion, facilitating their re-adsorption.

After the $\mathrm{CO}$ treatments, the selectivity for both catalysts is modified: the $\mathrm{C}_{5+}$ selectivity decreases, the $\mathrm{CH}_{4}$ and $\mathrm{CO}_{2}$ selectivity increases and the olefin selectivity slightly decreases. The chain growth probability is also significantly diminished after the treatments, as shown on Figure 10. These observations are in line with several studies [14,15,24-26] which reported a high productivity in light products and $\mathrm{CO}_{2}$ on carburized cobalt catalysts, and indicate that their observations were not due to conversion effects. The olefin selectivity decrease is yet contradictory to the conclusions of Zhong et al. [69], who obtained high olefin selectivity on $\mathrm{Co}_{2} \mathrm{C}$ nanoprismes. This study [69] was, however, not carried out at iso-conversion, and the authors showed later that this selectivity gain was highly dependent on the exposed facet [70,71]. The selectivity shift observed in our study is, moreover, dependant on the amount of cobalt carbide formed, the $230^{\circ} \mathrm{C}$ treatment modifying to a greater extent the selectivity than the $220^{\circ} \mathrm{C}$ one. This correlation can be well seen in Figure 11, which shows the selectivity variations extrapolated at 50\% CO conversion as function of the extent of carburization (based on magnetisation measurements, Table 2). This trend, since based on the data of catalysts with different particle size, suggests no influence of the particle size on the deselectivation behaviour of cobalt catalysts. Deselectivation is quantitatively ruled by the amount of cobalt carbide formed. Furthermore, it is interesting to note that the $\mathrm{CH}_{4}$ and $\mathrm{C}_{5+}$ selectivity variations with $\mathrm{CO}$ conversion seem to be more pronounced after the treatments (Figure 9). This phenomenon might indicate an increased susceptibility of catalyst performances to water partial pressure, with possibly a change in its adsorption equilibrium. 

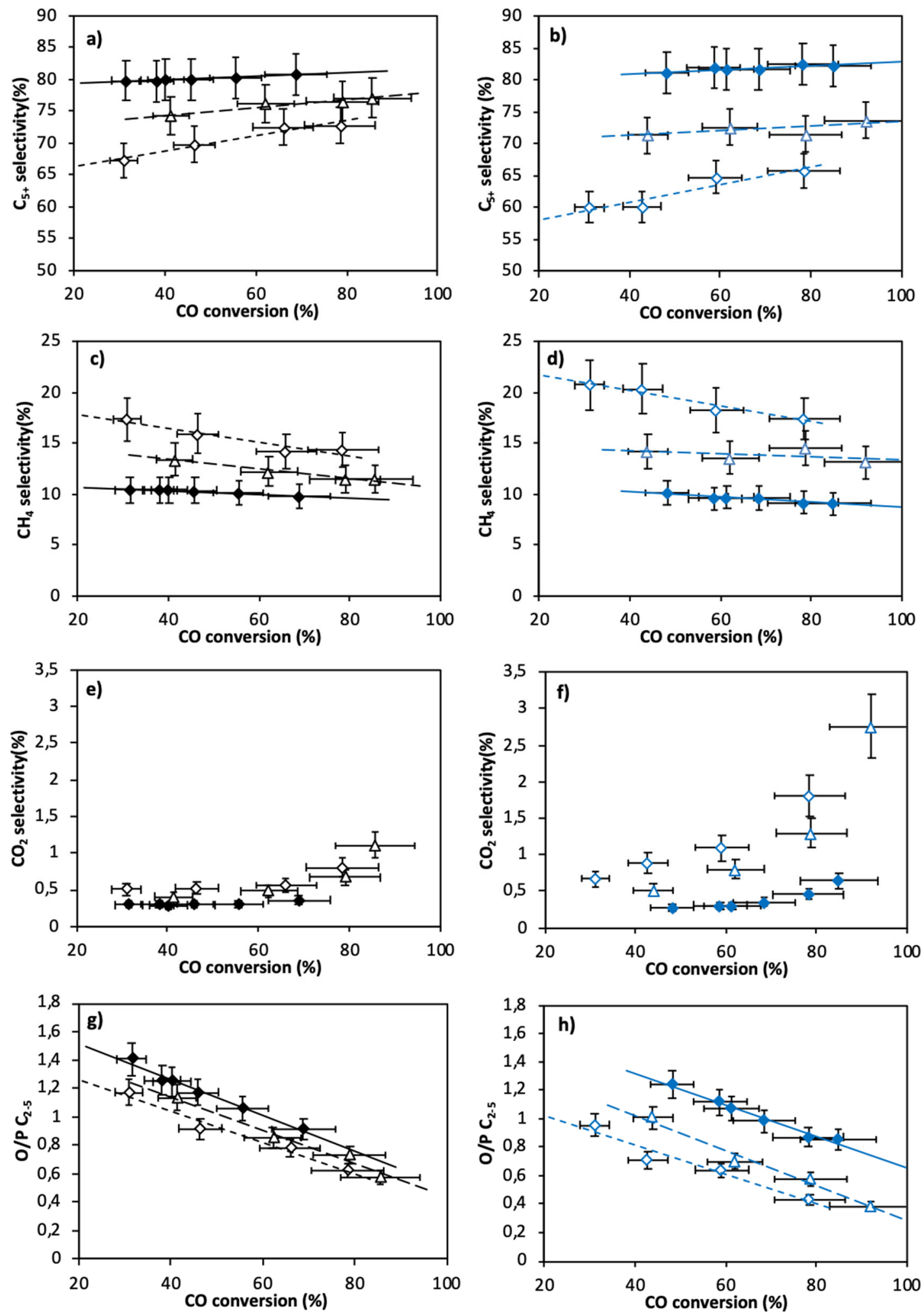

Figure 9: Co-18 (left) and Co-13 (right) catalysts selectivity in $\mathrm{CH}_{4}(\mathrm{a}, \mathrm{b}), \mathrm{C}_{5+}(\mathrm{c}, \mathrm{d}), \mathrm{CO}_{2}$ (e,f) and olefin/parrafin ratio of $\mathrm{C}_{2-}$

$\mathrm{C}_{5}(\mathrm{~g}, \mathrm{~h})$ as function of the $\mathrm{CO}$ conversion, at $20 \mathrm{barg}, 220^{\circ} \mathrm{C}, \mathrm{H}_{2} / \mathrm{CO}=2.12$. Solid and dashed lines are a guide to the eyes. 
This could be the reason why several studies reported a high alcohol selectivity [14,25,72-74], water dissociation generating $\mathrm{OH}$ groups at the surface that may be involved in the alcohol formation mechanism [74]. The analytical system used in the present study cannot however quantify accurately these alcohol products.

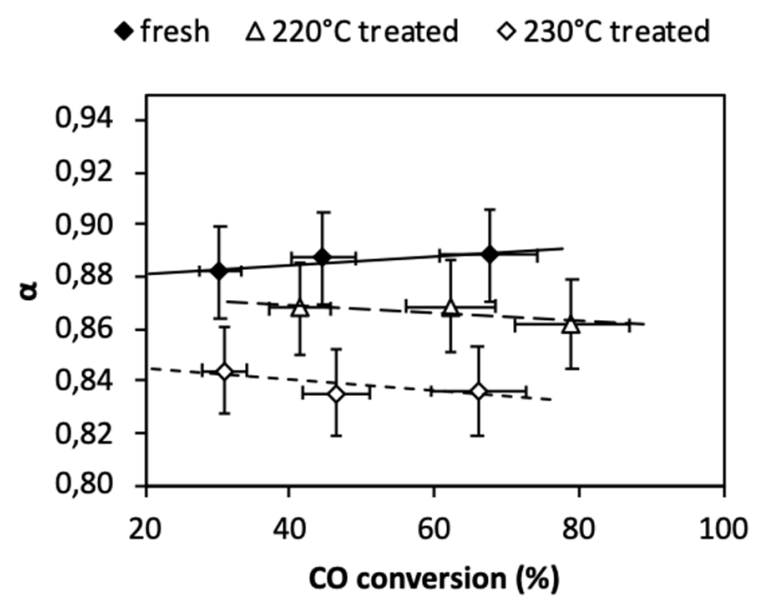

Figure 10: Co-18 catalyst chain growth probability as function of the $\mathrm{CO}$ conversion, at $20 \mathrm{barg}, 220^{\circ} \mathrm{C}, \mathrm{H}_{2} / \mathrm{CO}=2.12$. Solid and dashed lines are a guide to the eyes.

\section{Discussion}

Catalytic tests performed under industrial Fischer-Tropsch conditions showed that under the very same operating conditions (including a similar conversion level) the carburized catalysts have a lower activity than a fresh catalyst. We observed a higher deactivation level when the extent of carburization was increased. Because carburization was found to only concern the bulk phase and since no change of the particles size was observed, this deactivation is most likely due to an electronic effect of the bulk phase transformation on the surface phase. Catalytic tests also showed that carburization induces a severe deselectivation (i.e. a decrease in heavy compounds selectivity), depending on the amount of cobalt carbide formed. Several hypotheses can be formulated to explain the observed selectivity shift:

- Preferential site loss

- Surface coverage changes

- Intrinsic reactivity changes 

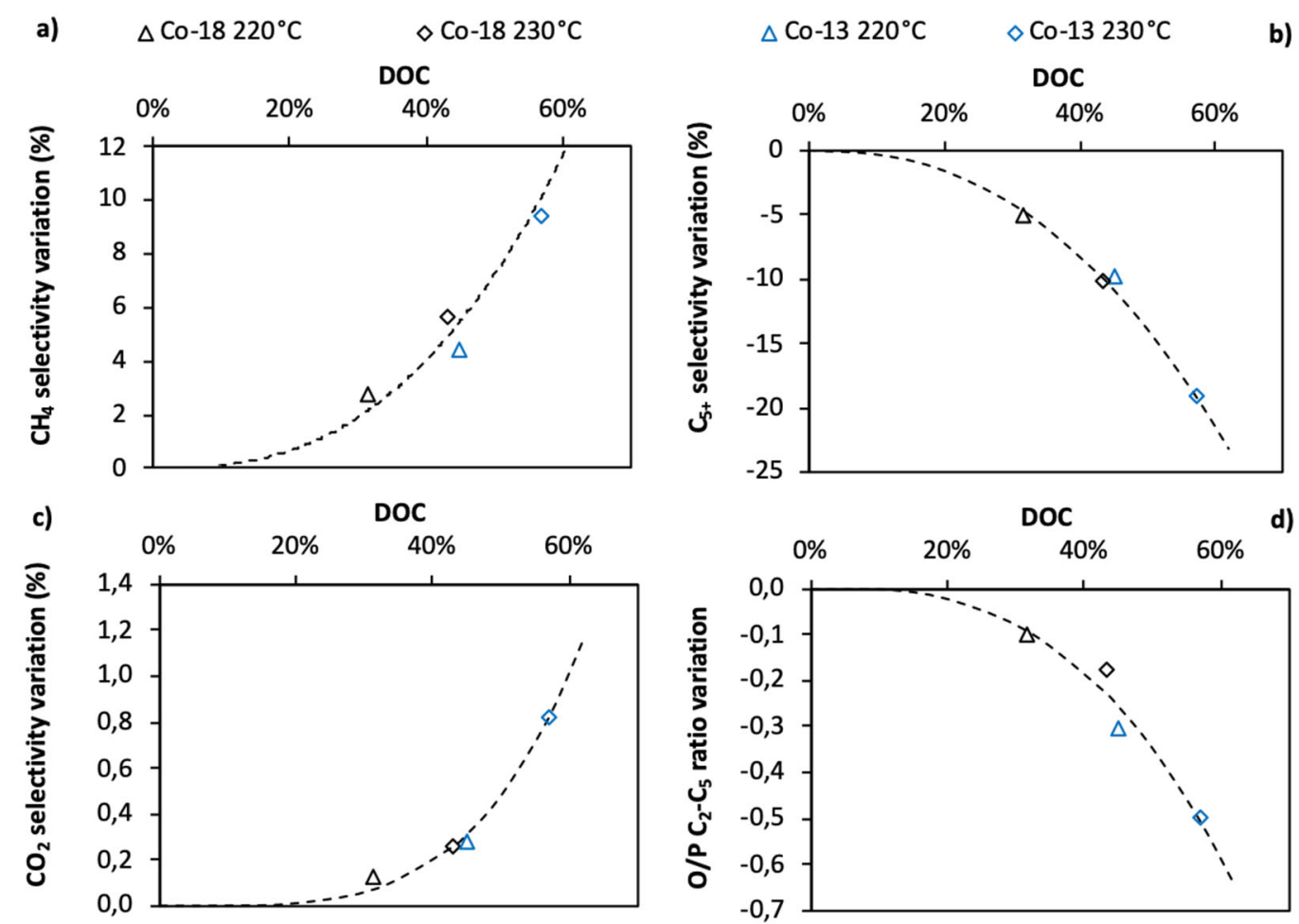

Figure 11: $\mathrm{CH}_{4}(\mathrm{a}), \mathrm{C}_{5+}$ (b), $\mathrm{CO}_{2}$ (c) and olefins (d) selectivity variations as function of degree of carburization (DOC) estimated by magnetisation measurements, at $220^{\circ} \mathrm{C}, 20$ barg, $\mathrm{H}_{2} / \mathrm{CO}=2.12$ and $50 \% \mathrm{CO}$ conversion.

In the literature numerous studies $[48,55,75-78]$ have proposed a model of reactivity with two different types of sites, one responsible for methanation and one for chain propagation. Schulz [78] suggested that chain propagation is mainly occurring on low-coordinated metallic sites (called "on-top") whereas methane is preferentially formed on planar sites. Chain termination and olefin re-adsorption were also assumed to occur on low coordinated sites. A similar model was proposed by Chen et al. [75] to explain the $\mathrm{CH}_{4}$ selectivity decrease they observed on a coke deposited catalyst. Coke was assumed to be selectively deposited on terraces (i.e. planar sites) and thus poisoned the methanation sites. This two-sites model might yet appear contradictory to the well-known observations of De Jong and coworkers $[61,62]$ who associated small particles $(<8 \mathrm{~nm})$ with high methane selectivity. Small particles present indeed a higher fraction of step sites compared to big particles [79], and should thus be less methane selective. Zhan et al. [55] found however an explanation to this surprising behavior: using DFT calculations, they showed that the step sites could not be stabilized on small particles in the presence of carbon at the surface. Nevertheless, and regardless to the nature of the site, the two-site model seem not to be at the origin of the carbide-induced deselectivation. The two main CO adsorption modes observed herein by DRIFTS (linear and bridged/multibonded), which probe different site configurations, are quantitatively affected to the same extent by the $\mathrm{CO}$ treatment. Thus, even if these two sites are responsible for different reactions, they are impacted in the same proportions by carburization and no selectivity change should be expected.

The adsorption of $\mathrm{CO}$ or other reactants or intermediates, such as hydrogen or water, could be impacted by the cobalt carbide formation and modify the surface compositions. This hypothesis is supported by the 
increased sensitivity of selectivity to the $\mathrm{CO}$ conversion level, indicating a more intense water effect, possibly due to its adsorption facilitation. Water gas shift reaction was also found to be enhanced on carburized catalysts, which comfort the fact that water adsorption is probably facilitated on cobalt carbide. The change in the olefin to paraffin ratio might indicate a change in the hydrogen adsorption strength. The hydrogen adsorption strength will also effect the methane selectivity and the chain growth.

Besides adsorption equilibrium changes, elementary reactions of the FT reaction scheme could also be altered by carburization (i.e. methanation, chains propagation and termination, readsorption). However, to evaluate their respective involvement in the selectivity shift, one should consider either co-injection experiments as it has sometimes been performed for water [80-82] or olefins [83], or the use of a microkinetic model, which can discriminate quantitatively the most plausible elementary reactions responsible for a selectivity change.

\section{Conclusions}

Carburization of cobalt catalysts was successfully performed using $\mathrm{CO}$ treatments without significant carbon deposition by low treatment temperatures $\left(<250^{\circ} \mathrm{C}\right)$. Particle size influences the extent of carburization possibly due to a core-shell model, and increasing temperature was found to accelerate the process. In-situ techniques (magnetization, DRIFTS) showed, moreover, that the phenomenon was not entirely reversible under syngas and conventional Fischer-Tropsch temperatures. CO treatments induced a severe deactivation of the catalysts, which was more important for the catalyst containing small particles due to a higher extent of carburization. Besides, the performance decay was not entirely proportional to the amount of metallic cobalt carburized, since a decrease of the intrinsic activity was measured as well. Additionally, an important deselectivation was observed: the methane and $\mathrm{CO}_{2}$ selectivities increased whereas the $\mathrm{C}_{5+}$ selectivity and chain growth probability severely decreased, while the olefin selectivity was slightly diminished. The mechanism involved behind this selectivity shift is not clear yet, but DRIFTS results indicated that the two-site model, sometimes used to rationalize the FTS selectivity, cannot be applied in this case. Carburization of the cobalt catalyst might thus be responsible for the long term deselectivation observed in Fischer-Tropsch synthesis, still it may not be the only process that induces this selectivity loss. Carbon deposition and water effect have also to be studied.

\section{Acknowledgements}

The authors would like to thank IFP Energies Nouvelles for financial support. Catalytic tests were conducted on the high-throughput heterogeneous catalytic platform located on Axel'One Campus facilities.

\section{References}

[1] S.S. Gill, A. Tsolakis, K.D. Dearn, J. Rodríguez-Fernández, Combustion characteristics and emissions of Fischer-Tropsch diesel fuels in IC engines, Progress in Energy and Combustion Science 37 (2011) 503-523.

[2] A.Y. Khodakov, W. Chu, P. Fongarland, Advances in the development of novel cobalt Fischer-Tropsch catalysts for synthesis of longchain hydrocarbons and clean fuels, Chemical reviews 107 (2007) 1692-1744. 
[3] H. Jahangiri, J. Bennett, P. Mahjoubi, K. Wilson, S. Gu, A review of advanced catalyst development for Fischer-Tropsch synthesis of hydrocarbons from biomass derived syn-gas, Catal. Sci. Technol. 4 (2014) 2210-2229.

[4] N.E. Tsakoumis, M. Rønning, Ø. Borg, E. Rytter, A. Holmen, Deactivation of cobalt based Fischer-Tropsch catalysts, Catalysis Today 154 (2010) 162-182.

[5] C. Boyer, J. Gazarian, V. Lecocq, S. Maury, A. Forret, J.M. Schweitzer, V. Souchon, Development of the Fischer-Tropsch Process: From the Reaction Concept to the Process Book, Oil Gas Sci. Technol. - Rev. IFP Energies nouvelles 71 (2016) 44.

[6] van der Laan, Gerard P., Beenackers, A. A. C. M., Kinetics and Selectivity of the Fischer-Tropsch Synthesis, Catalysis Reviews 41 (1999) 255-318.

[7] Branislav Todic, Wenping Ma, Gary Jacobs, Burtron H. Davis, Dragomir B. Bukur, Effect of process conditions on the product distribution of Fischer-Tropsch synthesis over a Re-promoted cobalt-alumina catalyst using a stirred tank slurry reactor, Journal of Catalysis 311 (2014) 325-338.

[8] E. Rytter, A. Holmen, Deactivation and Regeneration of Commercial Type Fischer-Tropsch Co-Catalysts-A Mini-Review, Catalysts 5 (2015) 478-499.

[9] D.J. Moodley, J. van de Loosdrecht, A.M. Saib, M.J. Overett, A.K. Datye, J.W. Niemantsverdriet, Carbon deposition as a deactivation mechanism of cobalt-based Fischer-Tropsch synthesis catalysts under realistic conditions, Applied Catalysis A: General 354 (2009) 102-110.

[10] C.-I. Ahn, H.M. Koo, M. Jin, J.M. Kim, T. Kim, Y.-W. Suh, K.J. Yoon, J.W. Bae, Catalyst deactivation by carbon formation during CO hydrogenation to hydrocarbons on mesoporous Co304, Microporous and Mesoporous Materials 188 (2014) 196-202.

[11] K. Keyvanloo, M.J. Fisher, W.C. Hecker, R.J. Lancee, G. Jacobs, C.H. Bartholomew, Kinetics of deactivation by carbon of a cobalt Fischer-Tropsch catalyst, Journal of Catalysis 327 (2015) 33-47.

[12] C.J. Weststrate, I.M. Ciobîcă, A.M. Saib, D.J. Moodley, J.W. Niemantsverdriet, Fundamental issues on practical Fischer-Tropsch catalysts, Catalysis Today 228 (2014) 106-112.

[13] O. Ducreux, J. Lynch, B. Rebours, M. Roy, P. Chaumette, In Situ Characterisation of Cobalt Based Fischer-Tropsch Catalysts, in: A. Parmaliana (Ed.), Natural gas conversion V: Proceedings of the Fifth International Natural Gas Conversion Symposium, Giardini Naxos-Taormina, Italy, September 20-25, 1998, Elsevier, Amsterdam, New York, 1998, pp. 125-130.

[14] Y. Dai, F. Yu, Z. Li, Y. An, T. Lin, Y. Yang, L. Zhong, H. Wang, Y. Sun, Effect of Sodium on the Structure-Performance Relationship of Co/SiO 2 for Fischer-Tropsch Synthesis, Chin. J. Chem. 35 (2017) 918-926.

[15] M. Claeys, M.E. Dry, E. van Steen, E. Du Plessis, P.J. van Berge, A.M. Saib, D.J. Moodley, In situ magnetometer study on the formation and stability of cobalt carbide in Fischer-Tropsch synthesis, Journal of Catalysis 318 (2014) 193-202.

[16] C. Lancelot, V.V. Ordomsky, O. Stéphan, M. Sadeqzadeh, H. Karaca, M. Lacroix, D. Curulla-Ferré, F. Luck, P. Fongarland, A. GribovalConstant, A.Y. Khodakov, Direct Evidence of Surface Oxidation of Cobalt Nanoparticles in Alumina-Supported Catalysts for FischerTropsch Synthesis, ACS Catal 4 (2014) 4510-4515.

[17] A.M. Saib, D.J. Moodley, I.M. Ciobîcă, M.M. Hauman, B.H. Sigwebela, C.J. Weststrate, J.W. Niemantsverdriet, J. van de Loosdrecht, Fundamental understanding of deactivation and regeneration of cobalt Fischer-Tropsch synthesis catalysts, Catalysis Today 154 (2010) 271-282.

[18] J. Clarkson, P.R. Ellis, R. Humble, G.J. Kelly, M. McKenna, J. West, Deactivation of alumina supported cobalt FT catalysts during testing in a Continuous-stirred tank reactor (CSTR), Applied Catalysis A: General 550 (2018) 28-37.

[19] G.W. Huber, C.G. Guymon, T.L. Conrad, B.C. Stephenson, C.H. Bartholomew, Hydrothermal Stability of Co/SiO2 Fischer-Tropsch Synthesis Catalysts, in: J.J. Spivey, G.W. Roberts, B.H. Davis (Eds.), Catalyst Deactivation 2001, Elsevier, 2001, pp. 423-430.

[20] A.-M. Hilmen, O.A. Lindvåg, E. Bergene, D. Schanke, S. Eri, A. Holmen, Selectivity and activity changes upon water addition during Fischer-Tropsch synthesis, in: E. Iglesia, J. Spivey, T. Fleisch (Eds.), Studies in Surface Science and Catalysis Natural Gas Conversion VI, Elsevier, 2001, pp. 295-300.

[21] C.H. Bartholomew, R.M. Bowman, Sulfur poisoning of cobalt and iron fischer-tropsch catalysts, Applied Catalysis 15 (1985) $59-67$.

[22] Stephen C. Leviness, Charles J. Mart, William C. Behrmann, Stephen J. Hsia, Daniel R. Neskora, Slurry hydrocarbon synthesis process with increased catalyst life, US6284807B1 (2001), ExxonMobil Research and Engineering Co.

[23] G.A. Somorjai, M.A. van Hove, Adsorbate-induced restructuring of surfaces, Progress in Surface Science 30 (1989) $201-231$.

[24] J.C. Mohandas, M.K. Gnanamani, G. Jacobs, W. Ma, Y. Ji, S. Khalid, B.H. Davis, Fischer-Tropsch Synthesis, ACS Catal. 1 (2011) 15811588.

[25] Y.-P. Pei, J.-X. Liu, Y.-H. Zhao, Y.-J. Ding, T. Liu, W.-D. Dong, H.-J. Zhu, H.-Y. Su, L. Yan, J.-L. Li, W.-X. Li, High Alcohols Synthesis via Fischer-Tropsch Reaction at Cobalt Metal/Carbide Interface, ACS Catal. 5 (2015) 3620-3624.

[26] Y. Pei, Y. Ding, H. Zhu, J. Zang, X. Song, W. Dong, T. Wang, L. Yan, Y. Lu, Study on the effect of alkali promoters on the formation of cobalt carbide (Co2C) and on the performance of Co2C via CO hydrogenation reaction, Reac Kinet Mech Cat 111 (2014) 505-520.

[27] R.B. Anderson, W.K. Hall, A. Krieg, B. Seligman, Studies of the Fischer--Tropsch Synthesis. V. Activities and Surface Areas of Reduced and Carburized Cobalt Catalysts, J. Am. Chem. Soc. 71 (1949) 183-188. 
[28] J. Nakamura, I. Toyoshima, K. Tanaka, Formation of carbidic and graphite carbon from CO on polycrystalline cobalt, Surface Science 201 (1988) 185-194.

[29] D. Peña, A. Griboval-Constant, V. Lecocq, F. Diehl, A.Y. Khodakov, Influence of operating conditions in a continuously stirred tank reactor on the formation of carbon species on alumina supported cobalt Fischer-Tropsch catalysts, Catalysis Today 215 (2013) $43-$ 51.

[30] W.L. Roth, The magnetic structure of Co304, Journal of Physics and Chemistry of Solids 25 (1964) 1-10.

[31] L.J.E. Hofer, E.M. Cohn, W.C. Peebles, Isothermal Decomposition of the Carbide in a Carburized Cobalt Fischer-Tropsch Catalyst, J. Phys. Chem. 53 (1949) 661-669.

[32] P. Cossee, Magnetic properties of cobalt in oxide lattices, Journal of Inorganic and Nuclear Chemistry 8 (1958) $483-488$.

[33] Peter Mohn, Magnetism in the Solid State An Introduction, Springer Science \& Business Media, 2006.

[34] M. Wolf, N. Fischer, M. Claeys, Effectiveness of catalyst passivation techniques studied in situ with a magnetometer, Catalysis Today 275 (2016) 135-140.

[35] P. Hazemann, D. Decottignies, S. Maury, S. Humbert, A. Berliet, C. Daniel, Y. Schuurman, Kinetic data acquisition in high-throughput Fischer-Tropsch experimentation, Catal. Sci. Technol. 10 (2020) 7331-7343.

[36] R.B. Anderson, R.A. Friedel, H.H. Storch, Fischer-Tropsch Reaction Mechanism Involving Stepwise Growth of Carbon Chain, The Journal of Chemical Physics 19 (1951) 313-319.

[37] P.G. Dimitrova, D.R. Mehandjiev, Active Surface of Y-Al2O3-Supported Co3O4, Journal of Catalysis 145 (1994) 356-363.

[38] M. Rønning, N.E. Tsakoumis, A. Voronov, R.E. Johnsen, P. Norby, W. van Beek, $\varnothing$. Borg, E. Rytter, A. Holmen, Combined XRD and XANES studies of a Re-promoted $\mathrm{Co} / \mathrm{Y}$-Al2O3 catalyst at Fischer-Tropsch synthesis conditions, Recent Developments in Operando Spectroscopy 155 (2010) 289-295.

[39] D.J. Moodley, A.M. Saib, J. van de Loosdrecht, C.A. Welker-Nieuwoudt, B.H. Sigwebela, J.W. Niemantsverdriet, The impact of cobalt aluminate formation on the deactivation of cobalt-based Fischer-Tropsch synthesis catalysts, Catalysis Today 171 (2011) $192-200$.

[40] A. SAIB, A. BORGNA, J. VANDELOOSDRECHT, P. VANBERGE, J. NIEMANTSVERDRIET, XANES study of the susceptibility of nano-sized cobalt crystallites to oxidation during realistic Fischer-Tropsch synthesis, Applied Catalysis A: General 312 (2006) 12-19.

[41] J. van de Loosdrecht, B. Balzhinimaev, J.-A. Dalmon, J.W. Niemantsverdriet, S.V. Tsybulya, A.M. Saib, P.J. van Berge, J.L. Visagie, Cobalt Fischer-Tropsch synthesis, Catalysis Today 123 (2007) 293-302.

[42] J.-A. Dalmon, Magnetic measurement and catalysis, in: Catalyst characterization Physical techniques for solid materials, pp. 585609.

[43] T. Hill, M. Mozaffari-Afshar, J. Schmidt, T. Risse, S. Stempel, M. Heemeier, H.-J. Freund, Influence of CO adsorption on the magnetism of small Co particles deposited on Al2O3, Chemical Physics Letters 292 (1998) 524-530.

[44] B. Li, Q. Zhang, L. Chen, P. Cui, X. Pan, Vacancy-mediated diffusion of carbon in cobalt and its influence on CO activation, Physical chemistry chemical physics PCCP 12 (2010) 7848-7855.

[45] L. Braconnier, E. Landrivon, I. Clémençon, C. Legens, F. Diehl, Y. Schuurman, How does activation affect the cobalt crystallographic structure?, Catalysis Today 215 (2013) 18-23.

[46] D. Moodley, M. Claeys, E. van Steen, P. van Helden, D. Kistamurthy, K.-J. Weststrate, H. Niemantsverdriet, A. Saib, W. Erasmus, J. van de Loosdrecht, Sintering of cobalt during FTS: Insights from industrial and model systems, Catalysis Today 342 (2020) 59-70.

[47] A. Paredes-Nunez, D. Lorito, Y. Schuurman, N. Guilhaume, F.C. Meunier, Origins of the poisoning effect of chlorine on the CO hydrogenation activity of alumina-supported cobalt monitored by operando FT-IR spectroscopy, Journal of Catalysis 329 (2015) 229-236.

[48] R.A. van Santen, A.J. Markvoort, I.A.W. Filot, M.M. Ghouri, E.J.M. Hensen, Mechanism and microkinetics of the Fischer-Tropsch reaction, Physical chemistry chemical physics PCCP 15 (2013) 17038-17063.

[49] A. Paredes-Nunez, D. Lorito, N. Guilhaume, C. Mirodatos, Y. Schuurman, F.C. Meunier, Nature and reactivity of the surface species observed over a supported cobalt catalyst under CO/H2 mixtures, Catalysis Today 242 (2015) 178-183.

[50] J. Couble, D. Bianchi, Experimental Microkinetic Approach of the Surface Reconstruction of Cobalt Particles in Relationship with the CO/H 2 Reaction on a Reduced 10\% Co/Al 2 O 3 Catalyst, J. Phys. Chem. C 117 (2013) 14544-14557.

[51] M.J. Dees, T. Shido, Y. Iwasawa, V. Ponec, Infrared studies of CO adsorbed on supported Pt · Co catalysts, Journal of Catalysis 124 (1990) 530-540.

[52] D. Song, J. Li, Q. Cai, In Situ Diffuse Reflectance FTIR Study of CO Adsorbed on a Cobalt Catalyst Supported by Silica with Different Pore Sizes, J. Phys. Chem. C 111 (2007) 18970-18979.

[53] H. Schulz, Z. Nie, F. Ousmanov, Construction of the Fischer-Tropsch regime with cobalt catalysts, Fischer-Tropsch synthesis on the eve of the XXI Century 71 (2002) 351-360.

[54] M. Corral Valero, P. Raybaud, Stability of Carbon on Cobalt Surfaces in Fischer-Tropsch Reaction Conditions, J. Phys. Chem. C 118 (2014) 22479-22490.

[55] X.-Q. Zhang, R.A. van Santen, E.J.M. Hensen, Carbon-Induced Surface Transformations of Cobalt, ACS Catal 5 (2015) $596-601$. 
[56] Q. Ge, M. Neurock, Adsorption and activation of CO over flat and stepped Co surfaces: a first principles analysis, The journal of physical chemistry. B 110 (2006) 15368-15380.

[57] A. Paredes-Nunez, D. Lorito, L. Burel, D. Motta-Meira, G. Agostini, N. Guilhaume, Y. Schuurman, F. Meunier, CO Hydrogenation on Cobalt-Based Catalysts, Angewandte Chemie (International ed. in English) 57 (2018) 547-550.

[58] W. Chen, B. Zijlstra, I.A.W. Filot, R. Pestman, E.J.M. Hensen, Mechanism of Carbon Monoxide Dissociation on a Cobalt FischerTropsch Catalyst, ChemCatChem 10 (2018) 136-140.

[59] B. Sarup, B.W. Wojciechowski, Studies of the fischer-tropsch synthesis on a cobalt catalyst II. Kinetics of carbon monoxide conversion to methane and to higher hydrocarbons, Can. J. Chem. Eng. 67 (1989) 62-74.

[60] P. Ghasvareh, K.J. Smith, Effects of Co Particle Size on the Stability of Co/Al 2 O 3 and Re-Co/Al 203 Catalysts in a Slurry-Phase Fischer-Tropsch Reactor, Energy Fuels 30 (2016) 9721-9729.

[61] G.L. Bezemer, J.H. Bitter, Kuipers, Herman P. C. E., H. Oosterbeek, J.E. Holewijn, X. Xu, F. Kapteijn, A.J. van Dillen, K.P. de Jong, Cobalt Particle Size Effects in the Fischer-Tropsch Reaction Studied with Carbon Nanofiber Supported Catalysts, J. Am. Chem. Soc. 128 (2006) 3956-3964.

[62] J.P. den Breejen, P.B. Radstake, G.L. Bezemer, J.H. Bitter, V. Frøseth, A. Holmen, K.P.d. Jong, On the Origin of the Cobalt Particle Size Effects in Fischer-Tropsch Catalysis, J. Am. Chem. Soc. 131 (2009) 7197-7203.

[63] Ø. Borg, P.D. Dietzel, A.I. Spjelkavik, E.Z. Tveten, J.C. Walmsley, S. Diplas, S. Eri, A. Holmen, E. Rytter, Fischer-Tropsch synthesis: Cobalt particle size and support effects on intrinsic activity and product distribution, Journal of Catalysis 259 (2008) $161-164$.

[64] A. Lillebø, E. Rytter, E.A. Blekkan, A. Holmen, Fischer-Tropsch Synthesis at High Conversions on Al2O3-Supported Co Catalysts with Different H2/CO Levels, Ind. Eng. Chem. Res. 56 (2017) 13281-13286.

[65] E. Iglesia, Design, synthesis, and use of cobalt-based Fischer-Tropsch synthesis catalysts, Applied Catalysis A: General 161 (1997) 59-78.

[66] D.B. Bukur, Z. Pan, W. Ma, G. Jacobs, B.H. Davis, Effect of CO Conversion on the Product Distribution of a Co/Al2O3 Fischer-Tropsch Synthesis Catalyst Using a Fixed Bed Reactor, Catal Lett 142 (2012) 1382-1387.

[67] Jinlin Li, Xiaodong Zhan, Yongqing Zhang, Gary Jacobs, Tapan Das, Burtron H Davis, Fischer-Tropsch synthesis: effect of water on the deactivation of Pt promoted Co/Al2O3 catalysts, Applied Catalysis A: General 228 (2002) 203-212.

[68] S. Storsæter, $\varnothing$. Borg, E.A. Blekkan, A. Holmen, Study of the effect of water on Fischer-Tropsch synthesis over supported cobalt catalysts, Journal of Catalysis 231 (2005) 405-419.

[69] L. Zhong, F. Yu, Y. An, Y. Zhao, Y. Sun, Z. Li, T. Lin, Y. Lin, X. Qi, Y. Dai, L. Gu, J. Hu, S. Jin, Q. Shen, H. Wang, Cobalt carbide nanoprisms for direct production of lower olefins from syngas, Nature 538 (2016) 84-87.

[70] Z. Li, T. Lin, F. Yu, Y. An, Y. Dai, S. Li, L. Zhong, H. Wang, P. Gao, Y. Sun, M. He, Mechanism of the Mn Promoter via CoMn Spinel for Morphology Control: Formation of Co 2 C Nanoprisms for Fischer-Tropsch to Olefins Reaction, ACS Catal. 7 (2017) $8023-8032$.

[71] Z. Li, L. Zhong, F. Yu, Y. An, Y. Dai, Y. Yang, T. Lin, S. Li, H. Wang, P. Gao, Y. Sun, M. He, Effects of Sodium on the Catalytic Performance of CoMn Catalysts for Fischer-Tropsch to Olefin Reactions, ACS Catal. 7 (2017) 3622-3631.

[72] G. Jiao, Y. Ding, H. Zhu, X. Li, J. Li, R. Lin, W. Dong, L. Gong, Y. Pei, Y. Lu, Effect of La2O3 doping on syntheses of C1-C18 mixed linear $\alpha$-alcohols from syngas over the Co/AC catalysts, Applied Catalysis A: General 364 (2009) 137-142.

[73] Y. Liu, S. He, R. Yang, F. Sun, Y. Yang, B. Mei, J. Kang, D. Wu, Z. Jiang, Tuning the interfaces of Co-Co2C with sodium and its relation to the higher alcohol production in Fischer-Tropsch synthesis, Journal of Materials Science 55 (2020) 9037-9047.

[74] M.K. Gnanamani, G. Jacobs, U.M. Graham, M.C. Ribeiro, F.B. Noronha, W.D. Shafer, B.H. Davis, Influence of carbide formation on oxygenates selectivity duringFischer-Tropsch synthesis over Ce-containing Co catalysts, Catalysis Today 261 (2016) $40-47$.

[75] W. Chen, T.F. Kimpel, Y. Song, F.-K. Chiang, B. Zijlstra, R. Pestman, P. Wang, E.J.M. Hensen, Influence of Carbon Deposits on the Cobalt-Catalyzed Fischer-Tropsch Reaction: Evidence of a Two-Site Reaction Model, ACS catalysis 8 (2018) 1580-1590.

[76] I.M. Ciobica, R.A. van Santen, Carbon Monoxide Dissociation on Planar and Stepped Ru(0001) Surfaces, J. Phys. Chem. B 107 (2003) 3808-3812.

[77] S. Lögdberg, M. Lualdi, S. Järås, J.C. Walmsley, E.A. Blekkan, E. Rytter, A. Holmen, On the selectivity of cobalt-based Fischer-Tropsch catalysts, Journal of Catalysis 274 (2010) 84-98.

[78] H. Schulz, Major and Minor Reactions in Fischer-Tropsch Synthesis on Cobalt Catalysts, Topics in Catalysis 26 (2003) $73-85$.

[79] R. Van Hardeveld, F. Hartog, The statistics of surface atoms and surface sites on metal crystals, Surface Science 15 (1969) $189-230$.

[80] Jinlin Li, Gary Jacobs, Tapan Das, Yongqing Zhang, Burtron Davis, Fischer-Tropsch synthesis: effect of water on the catalytic properties of a Co/SiO2 catalyst, Applied Catalysis A: General 236 (2002) 67-76.

[81] Gabor Kiss, Chris E. Kliewer, Gregory J. DeMartin, Claude C. Culross, Joseph E. Baumgartner, Hydrothermal deactivation of silicasupported cobalt catalysts in Fischer-Tropsch synthesis, Journal of Catalysis 217 (2003) 127-140.

[82] H. Schulz, M. Claeys, S. Harms, Effect of water partial pressure on steady state Fischer-Tropsch activity and selectivity of a promoted cobalt catalyst, in: M. de Pontes, R.L. Espinoza, C.P. Nicolaides, J.H. Scholtz, M.S. Scurrell (Eds.), Natural Gas Conversion IV, Elsevier, 1997, pp. 193-200. 
[83] V. Sage, Y. Sun, P. Hazewinkel, T. Bhatelia, L. Braconnier, L. Tang, K. Chiang, M. Batten, N. Burke, Modified product selectivity in Fischer-Tropsch synthesis by catalyst pre-treatment, Fuel Processing Technology 167 (2017) 183-192. 